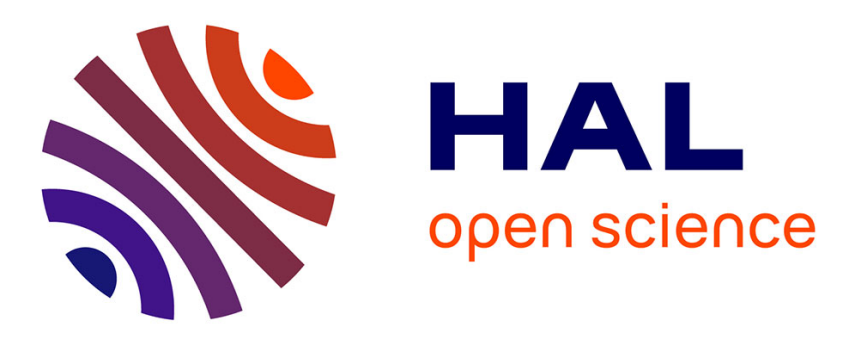

\title{
Simplified stress analysis of hybrid (bolted/bonded) joints
}

\author{
Eric Paroissien, Frederic Lachaud, Sébastien Schwartz, Anthony da Veiga, \\ Patrick Barrière
}

\section{- To cite this version:}

Eric Paroissien, Frederic Lachaud, Sébastien Schwartz, Anthony da Veiga, Patrick Barrière. Simplified stress analysis of hybrid (bolted/bonded) joints. International Journal of Adhesion and Adhesives, 2017, 77, pp.183-197. 10.1016/j.ijadhadh.2017.05.003 . hal-01543283

\section{HAL Id: hal-01543283 \\ https://hal.science/hal-01543283}

Submitted on 20 Jun 2017

HAL is a multi-disciplinary open access archive for the deposit and dissemination of scientific research documents, whether they are published or not. The documents may come from teaching and research institutions in France or abroad, or from public or private research centers.
L'archive ouverte pluridisciplinaire HAL, est destinée au dépôt et à la diffusion de documents scientifiques de niveau recherche, publiés ou non, émanant des établissements d'enseignement et de recherche français ou étrangers, des laboratoires publics ou privés. 


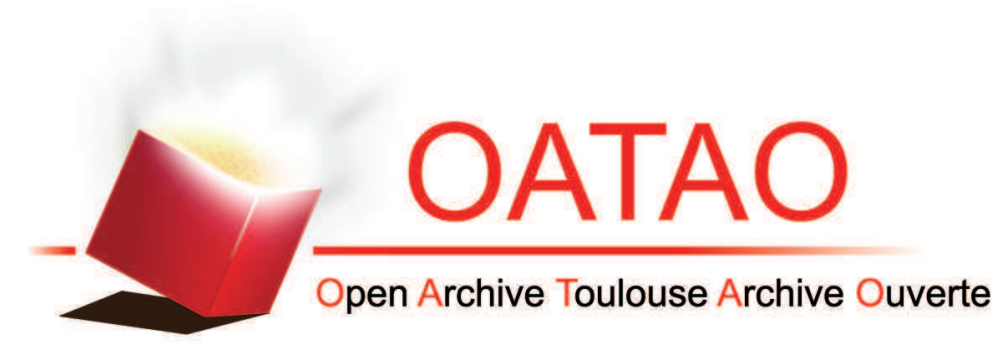

\section{Open Archive Toulouse Archive Ouverte (OATAO)}

OATAO is an open access repository that collects the work of some Toulouse researchers and makes it freely available over the web where possible.

This is an author's version published in: https://oatao.univ-toulouse.fr/17908

Official URL:https://doi.org/10.1016/j.ijadhadh.2017.05.003

\section{To cite this version :}

Paroissien, Eric and Lachaud, Frédéric and Schwartz, Sébastien and Da Veiga, Anthony and Barrière, Patrick Simplified stress analysis of hybrid (bolted/bonded) joints. (2017) International Journal of Adhesion and Adhesives, vol. 77. pp. 183-197. ISSN 0143-7496

Any correspondence concerning this service should be sent to the repository administrator: tech-oatao@listes-diff.inp-toulouse.fr 


\section{SIMPLIFIED STRESS ANALYSIS OF HYBRID (BOLTED/BONDED) JOINTS}

2

3

4

5

6

7

8

9

10 11

12

13

14

15

16

17

18

19

20

21 *To whom correspondence should be addressed:

22 E-mail: eric.paroissien@isae-supaero.fr

23

Postal Address: Institut Clément Ader (ICA), BR1.023, 3 Rue Caroline Aigle, 31400

24 TOULOUSE, FRANCE

$25 \quad$ Tel. +33561171093

26 Fax number : +33561171080

${ }^{1}$ Institut Clément Ader (ICA), Université de Toulouse, CNRS-INSA-ISAE-Mines Albi-UPS, Toulouse, France

2SOGETI HIGH TECH, AEROPARK, 3 Chemin Laporte, 31300 TOULOUSE, FRANCE 1

E. PAROISSIEN ${ }^{1, *}$, F. LACHAUD ${ }^{1}$, S. SCHWARTZ ${ }^{2}$, A. DA VEIGA ${ }^{2}$, P. BARRIERE ${ }^{2}$ 
1 Abstract - The load transfer in hybrid (bolted/bonded) - denoted HBB - single-lap joints

2 is complicated due to the association of two different transfer modes (discrete and 3 continuous) through elements with different stiffnesses. The Finite Element (FE) method

4 can be used to address the stress analysis of those joints. However, analyses based on

5 FE models are computationally expensive and it would be profitable to use simplified approaches enabling extensive parametric studies. Two among the authors of this paper participated in the development of a dedicated 1D-beam approach (Paroissien 2007). This paper presents an extension of this framework enabling (i) the analysis of HBB joints made of dissimilar laminated or monolithic adherends, and (ii) the introduction of non

10 linear material behaviour for both the adhesive layer and the fasteners. The output data are the distributions of displacements and forces in the adherends and fasteners, as well as those of adhesive shear and peeling stresses, allowing for a fast assessment of the material behaviour and strength prediction of HBB joints. The use of this model is illustrated in the identification of the failure mechanisms of HBB joints under quasistatic loadings, based on experimental and numerical tests on single-lap HBB joint. It is worth mentioning that the model can support pure bonded and pure bolted configurations. It can be used during the presizing phase at the design office (possibly independently on commercial software), to obtain quickly mechanical performances and to help in decision making. Moreover, it was shown that the judicious choice of the adhesive material allows for a significant increase of the static and fatigue strength compared to pure bolted or bonded corresponding configurations (Kelly 2006) (Paroissien 2006). The model can then be used to formulate at best adhesive materials to optimize the mechanical performance of HBB joints according to work specifications.

Key words: bolted joint, bonded joint, unbalanced joint, analytical solution, Finite 


\section{NOMENCALTURE AND UNITS}

2

$3 A_{j} \quad=$ extensional stiffness $(\mathrm{N})$ of the adherend $j$

$4 \quad B_{j} \quad=$ extensional and bending coupling stiffness (N.mm) of the adherend $j$

$5 \quad \mathrm{C}=$ stiffness $\left(\mathrm{N} \cdot \mathrm{mm}^{-1}\right)$

$6 C_{u}=$ stiffness $\left(\mathrm{N} \cdot \mathrm{mm}^{-1}\right.$ ) of the spring in the $\mathrm{x}$ direction (longitudinal stiffness)

$7 \quad C_{w} \quad=$ stiffness $\left(\mathrm{N} \cdot \mathrm{mm}^{-1}\right)$ of the spring in the $\mathrm{y}$ direction (transversal stiffness)

$8 C_{\theta} \quad=$ stiffness (N.mm.rad ${ }^{-1}$ ) of the spring around the $z$ direction (bending stiffness)

$9 D_{j} \quad=$ bending stiffness $\left(\mathrm{N} . \mathrm{mm}^{2}\right)$ of the adherend $j$

$10 E_{j} \quad=$ Young's modulus (MPa) of the adherend $j$

$11 E=$ adhesive peel modulus $(\mathrm{MPa})$

$12 E_{f} \quad=$ Young's modulus (MPa) of the fastener

$13 F=$ vector of forces

$14 G \quad=$ adhesive shear modulus $(\mathrm{MPa})$

$15 \mathrm{G} 1 \mathrm{C}=$ critical energy release rate in pure mode I (MPa.mm)

$16 \mathrm{G} 2 \mathrm{C}=$ critical energy release rate in pure mode II (MPa.mm)

$17 K=$ stiffness matrix

$18 L \quad=$ length $(\mathrm{mm})$ of the overlap

$19 M_{j} \quad=$ bending moment (N.mm) in the adherend $j$ around the $z$ direction

$20 N_{j} \quad=$ normal force $(\mathrm{N})$ in the adherend $j$ in the $x$ direction

$21 Q_{a} \quad=$ nodal normal force $(\mathrm{N})$ applied to the node $a$ in the $x$ direction $(a=i, j, k, l)$

$22 R_{a} \quad=$ nodal shear force (N) applied to the node $a$ in the $y$ direction $(a=i, j, k, l)$

$23 \mathrm{~S}=$ adhesive peel stress $(\mathrm{MPa})$

$24 S_{a}=$ nodal bending moment (N.mm) applied to the node $a$ around the $z$ direction

$25 \quad(a=i, j, k, l)$

$26 T=$ adhesive shear stress $(\mathrm{MPa})$

$27 U=$ vector of displacements

$28 V_{j} \quad=$ shear force $(\mathrm{N})$ in the adherend $j$ in the $y$ direction

$29 Y_{0}=$ elastic strain energy stored in pure mode 1 (MPa.mm) 


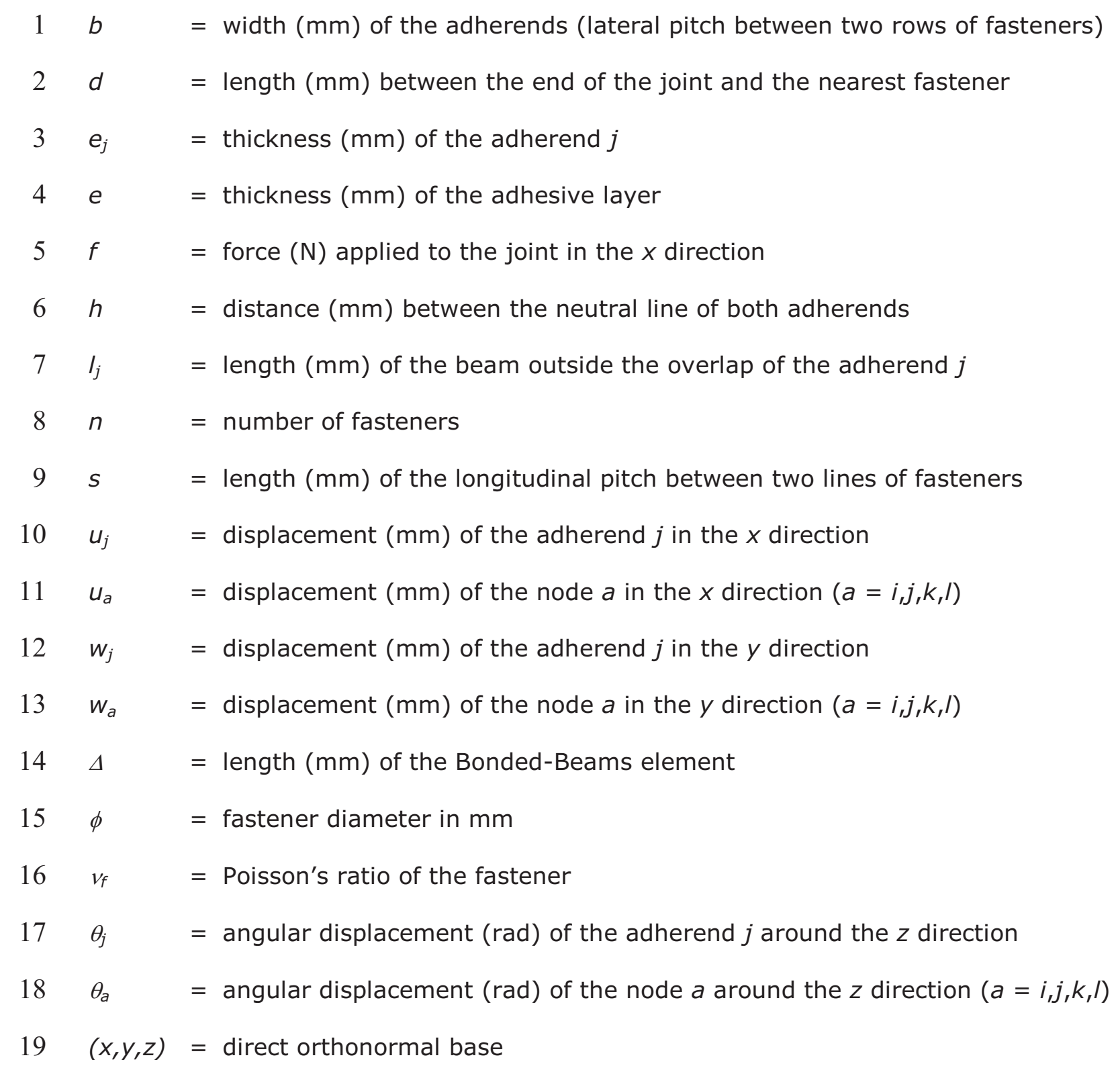




\section{1. INTRODUCTION}

2 Hybrid (bolted/bonded) - denoted HBB - joining technology in lap joints combines both 3 classical techniques, i.e. bolting and bonding. The advantages of HBB joints, compared to 4 bolted joints, could be summarised in two main points: (i) continuous instead of discrete load transfer distribution along the overlap, (ii) decrease of load transferred by fasteners. Hartman reported fatigue test results on single-lap joints of two similar aluminium 2024 bolted joints (Hartman 1966). Furthermore, in terms of security, the existence of fasteners in HBB joints could ensure the functioning of the structure, even if the adhesive layer failure occurs. In manufacturing industries, such as aerospace, automotive, rail or naval transport industries, in which numerous bolted and riveted joints are used, the use of HBB technology could be considered as a potential solution, in order to reduce the mass as well as the manufacturing cost. HBB joining technology was presented as a relevant concept of fail-safe structures by Hart-Smith (Hart-Smith 1982). According to this study, HBB joints with aerospace configurations and material systems do not offer any significant increase in strength compared to adhesively bonded joints, which could be explained by the low fraction of load transferred by the fasteners. Imanaka et al. showed that the fatigue strength of the adhesive joint can be improved through combination with a rivet whose fatigue strength is at least that of the corresponding bonded joint 20 (Imanaka 1995). Since 2000, along with the development of adhesive materials as well 21 as the increasing use of composites in industrial applications, some studies have been published on the mechanical performance of HBB joining technology. Fu and Mallick experimentally demonstrated that single-lap HBB joints with structural injection moulded

24 (SRIM) composite material for the adherends and epoxy material for the adhesive have a higher static strength and longer fatigue life than corresponding adhesively bonded joints (Fu 2001). However, this performance depends on the washer configuration. Washers, which provide partial lateral clamping pressure over the entire overlap area, have a better performance than those that provide partial lateral clamping pressure. Samaei et al. experimentally and numerically showed that the addition of an adhesive layer to a 
1 pure bolted joint made of aluminium alloy allows for the extension of fatigue crack 2 growth life (Samei 2016). Chowdhury et al. showed that HBB joints could lead to higher damage tolerance performances than pure bonded joints configurations, whereas no significant variation in the static strength is obtained (Chowdhury 2015). Kelly experimentally and numerically showed that as the load can be shared between the adhesive and the bolt by using low modulus adhesives, HBB joints can have greater static strength and fatigue life than corresponding adhesively bonded joints (Kelly 2006). By employing a low modulus adhesive, Paroissien experimentally obtained a significant improvement in fatigue life with double-lap HBB joints with two lines of fasteners compared to double-lap sealed and bolted joints with three lines of fasteners (Paroissien 2006). The judicious choice of the adhesive appears as determinant to optimize the static and fatigue performance of HBB joints. According to Raju et al., the use of interferencefit bolt promotes the load sharing between the adhesive layer and the fastening system (Raju 2016), as a key parameter to improve the mechanical performances of HBB joints. Kumar et al. provided a design improvement of single-lap composite HBB joints in term of static ultimate strength by adding attachments reducing the bending moment at both overlap ends (Kumar 2010).

The Finite Element (FE) method is able to address the stress analysis of HBB joints (Kelly 2006, Hoang-Ngoc 2010, Bois 2013). Nevertheless, analyses based on FE models are mainly computationally expensive and it would be profitable to develop simplified methods, enabling extensive parametric studies. Oterkus et al. presented a semianalytical tool for the three-dimensional analysis of a single-lap HBB joint with one fastener line, calculating the displacements and stresses in the joint and the load distribution near the contact region between the bolt and laminates (Oterkus 2007). It was found that most of the load is transferred through the adhesive layer, even if it has a low modulus as compared to the bolt. Besides, Paroissien et al. developed a framework enabling a semi-analytical 1D-beam (and 1D-bar) analysis of HBB joints (Paroissien 2006, Paroissien 2007). This framework is inspired by the FE method and based on the minimization of the potential energy. Macro-elements are formulated for the simulation 
1 of fasteners and the simulation of two bonded adherends, called bonded-beam (BB)

2 elements. This model allows for an easy mechanical behaviour analysis of single-lap HBB

3 joints, composed by any number of fastener lines. It provides the distributions of

4 displacements and forces in the adherends and the fasteners, as well as those of

5 adhesive shear and peeling stresses. In the frame of a parametric study, this analytical approach shows that a low modulus adhesive should be used, in order to share the load between the adhesive layer and the fasteners, in attempt to offer a significant improvement in fatigue life. Nevertheless, this 1D-beam model was restricted to joints made of two similar adherends and to linear elastic material behaviour. A new BB element, supporting two possible dissimilar laminated or monolithic adherends and

11 including non linear adhesive materials was then developed (Paroissien 2013a, Paroissien 2013b). Lélias et al. improved the non linear algorithm to include various non linear adhesive constitutive behaviours such as damage evolution law under mixed mode I/II 14 (Lélias 2015).

The objective of this paper is to take benefit from recent improvements performed on the BB elements, in order to provide an improved semi-analytical model of HBB joints. Moreover, a more efficient solution, in terms of computational time, for the simulation of fasteners is presented. An example of application on unbalanced configurations allows for the illustration of adhesive stress and adherend force distributions along the overlap. The use of this model to investigate the failure mechanisms of HBB joints under static load is then presented in this paper, based on an experimental test. Finally, a refined 3D FE model realised on ABAQUS-STANDARD is developed based on cohesive damage approach of adhesive behaviour. With the help of this 3D FE model, failure development can be explained and compared with 1D-Beam model.

\section{SEMI-ANALYTICAL MODEL OF HBB JOINTS}

\subsection{MACRO-ELEMENT TECHNIQUE OVERVIEW}

28 The method is inspired by the FE method and exemplified on the single-lap HBB joint. The single-lap HBB joint is meshed (see Figure 1) in elements. A 1D-beam kinematics is 
1 assumed so that each node has three degrees of freedom (DoF): two translations in the 2 plane according to both first axes and one rotation around the third axis. The parts 3 outside the overlap are simulated by beam elements. The fasteners are simulated by 4 special fastening elements (Paroissien 2007), as presented in section 2.3 of this paper. In the overlap, each bonded bay is simulated by an especially formulated macro-element, called bonded-beams (BB) element. This macro-element has four nodes (see Figure 2), in order to take into account the relative displacements of both bonded adherends. After finding the elementary stiffness matrices of each element type, the stiffness matrix denoted $K$ - of the full single-lap HBB joint is assembled. The boundary conditions are then introduced. The vector of displacements - denoted $U$ - and the vector of forces denoted $F$ - are determined. The stiffness matrix of the full joint is then updated following the classical rules of the FE method. For a linear elastic material, the minimization of the potential energy leads simply to the linear system $F=K U$. Considering non linear materials, an iterative procedure based on the linear elastic procedure is employed for the resolution. The mechanical and geometric parameters are free. In particular, the number of fastener lines is denoted $n$. To get the solution, a dedicated computer programme has to be implemented.

Considering the analysis of pure bonded joints, this approach can be regarded as another sandwich-type model for the analysis of bonded joints (Williams 1975, Bigwood 1989, Högberg 2004, Weissgraeber 2014), developed in particular to address the unbalanced configuration. Nevertheless, the presented approach supports the introduction of various boundary conditions at various locations, not only restricted to both overlap ends. Indeed, particular interests of the macro-element technique are the possibility both to address easily various geometrical configurations by simple manipulations on the stiffness matrix and to be implemented through user routines within commercial FE codes 26 (Stapelton 2012), to reduce computational time while keeping a satisfying level of 27 accuracy.

\subsection{BONDED-BEAMS ELEMENT}




\section{$1 \quad$ 2.2.1 Hypotheses and governing equations}

2 The formulation of the bonded-beams element is based on the following hypotheses.

3 Firstly, the thickness of the adhesive layer is constant along the overlap. Secondly, the

4 adherends are considered as laminated Euler-Bernoulli beams in the frame of the 5 classical laminated theory, and can be dissimilar. The constitutive equations are 6 expressed, as described by Mortensen and Thomsen (Mortensen 2002), by:

$7\left\{\begin{array}{l}N_{j}=A_{j} \frac{d u_{j}}{d x}-B_{j} \frac{d^{2} w_{j}}{d x^{2}} \\ M_{j}=-B_{j} \frac{d u_{j}}{d x}+D_{j} \frac{d^{2} w_{j}}{d x^{2}} \quad, j=1,2 \\ \theta_{j}=\frac{d w_{j}}{d x}\end{array}\right.$

8 where $N_{j}\left(M_{j}\right)$ is the normal force (bending moment) of the adherend $j$ and $u_{j}\left(w_{j}, \theta_{j}\right)$ is 9 the longitudinal displacement (deflection, bending angle) of the adherend $j$. For the

10 adherend $j, A_{j}$ represents the extensional stiffness, $D_{j}$ the bending stiffness and $B_{j}$ the 11 coupling stiffness.

12 The adhesive layer is simulated in the frame of the classical two-parameter elastic 13 foundation model (Goland 1944) and consists thus in continuously distributed shear and 14 peel springs. In other words, only two components of the adhesive stress tensor are 15 assumed different from zero. Moreover, the adhesive stresses are assumed constant 16 along the adhesive layer thickness. The adhesive shear stress - denoted $T$ - and the

17 adhesive peeling stress - denoted $S$ - are then given by:

$18\left\{\begin{array}{l}T=\frac{G}{e}\left(u_{2}-u_{1}-\frac{1}{2} e_{1} \theta_{1}-\frac{1}{2} e_{2} \theta_{2}\right) \\ S=\frac{E}{e}\left(w_{1}-w_{2}\right)\end{array}\right.$

19 where $G$ is the adhesive shear modulus, $E$ is the adhesive peel modulus (Lélias 2015) and

20 e the adhesive thickness.

21 The local equilibrium of both adherends (see Figure 3 ) leads to the system of six following differential equations: 
$1\left\{\begin{array}{l}\frac{d N_{j}}{b d x}=(-1)^{j} T \\ \frac{d V_{j}}{b d x}=(-1)^{j+1} S, j=1,2 \\ \frac{d M_{j}}{d x}+V_{i}+\frac{e_{j}}{2} b T=0\end{array}\right.$

2 where $V_{j}$ is the shear force of the adherend $j, e_{j}$ is the thickness of adherend $j$ and $b$ is

3 the width. This equilibrium corresponds to the equilibrium by Goland and Reissner

4 (Goland 1944).

5 The previous system of equations forms the governing equations of the bonded beams.

6

7

\subsubsection{Elementary Stiffness Matrix}

8 The coefficients of the stiffness matrix are obtained by differentiating each component of

9 the nodal forces by each component of the nodal displacements:

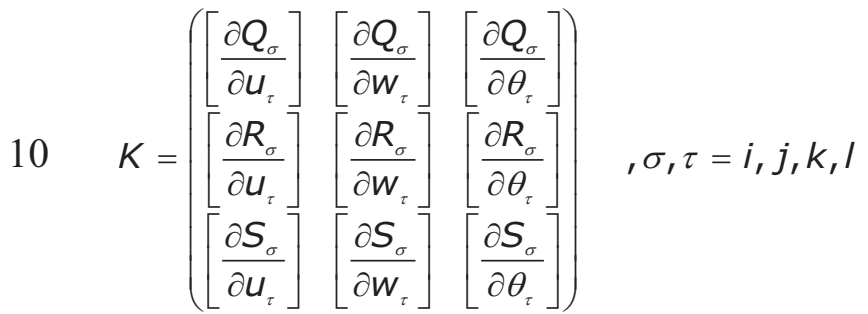

11 The detailed resolution scheme can be found in (Paroissien 2013a, Paroissien 2013b).

12 The main steps are then summarized in the Appendix A.

13

\subsection{SIMULATION OF FASTENERS}

15 The former simulation of fasteners consists in a rigid body element coupled with three

16 springs, the stiffnesses of which are termed $2 C_{u}, 2 C_{w}$ and $2 C_{\square}$ (Paroissien 2007). The

17 fastener $m$ is placed between the nodes $2(m+1)$ and $2(m+1)+1$ of the structure. The

18 partial stiffness matrix of the fastener $m$, termed $K_{u}^{m}$ linking the vector of nodal

19 displacements according to the x-axis ${ }^{t}\left(u_{2(m+1)} ; u_{2(m+1)+1} ; u_{r(m)} ; u_{s(m)}\right)$ and the vector of 20 nodal forces according to the x-axis ${ }^{t}\left(Q_{2(m+1)} ; Q_{2(m+1)+1} ; Q_{r(m)} ; Q_{s(m)}\right)$, is: 
$1 \quad K_{u}^{m}=2\left(\begin{array}{cccc}C_{u} & 0 & -C_{u} & 0 \\ 0 & C_{u} & 0 & -C_{u} \\ -C_{u} & 0 & C_{u} & 0 \\ 0 & -C_{u} & 0 & C_{u}\end{array}\right), m \in[1 ; n]$

2 Similar relationships are obtained for the partial stiffness matrices $K_{w}^{m}$ and $K_{\theta}^{m}$.

3 The nodes of the rigid body element are termed $r(m)$ and $s(m)$ as shown in Figure 4 . The

4 size of the stiffness matrix of the joint is then increased of $6 n$. The introduction of $n$ rigid 5 body elements induces the following $3 n$ associated kinematic relationships of linear 6 dependency:

$7 \quad\left\{\begin{array}{l}u_{s(m)}=u_{r(m)}+h \theta_{r(m)} \\ W_{s(m)}=W_{r(m)} \\ \theta_{s(m)}=\theta_{r(m)}\end{array}\right.$

8 where $h$ is the distance between the neutral lines (line of section centers) of both 9 adherends. The application of the master-slave method allows for the elimination of $3 n$ 10 on $6 n$ additional DoF. For example, the $n$ nodes $s(m)$ - then the $3 n$ DoF associated - are 11 assumed to be removed, without any generality loose. The nodal force vector can then 12 be expressed as functions of the nodal displacement vectors as follows:

$$
\left(\begin{array}{c}
Q_{2(m+1)} \\
Q_{2(m+1)+1} \\
Q_{r(m)} \\
R_{2(m+1)} \\
R_{2(m+1)+1} \\
R_{r(m)} \\
S_{2(m+1)} \\
S_{2(m+1)+1} \\
S_{r(m)}
\end{array}\right)=\left(\begin{array}{ccccccccc}
2 C_{u} & 0 & -2 C_{u} & 0 & 0 & 0 & 0 & 0 & 0 \\
0 & 2 C_{u} & -2 C_{u} & 0 & 0 & 0 & 0 & 0 & -2 h C_{u} \\
-2 C_{u} & -2 C_{u} & 4 C_{u} & 0 & 0 & 0 & 0 & 0 & 2 h C_{u} \\
0 & 0 & 0 & 2 C_{w} & 0 & -2 C_{w} & 0 & 0 & 0 \\
0 & 0 & 0 & 0 & 2 C_{w} & -2 C_{w} & 0 & 0 & 0 \\
0 & 0 & 0 & -2 C_{w} & -2 C_{w} & 4 C_{w} & 0 & 0 & 0 \\
0 & 0 & 0 & 0 & 0 & 0 & 2 C_{\theta} & 0 & -2 C_{\theta} \\
0 & 0 & 0 & 0 & 0 & 0 & 0 & 2 C_{\theta} & -2 C_{\theta} \\
0 & -2 h C_{u} & 2 h C_{u} & 0 & 0 & 0 & -2 C_{\theta} & -2 C_{\theta} & 2 h^{2} C_{u}+4 C_{\theta}
\end{array}\right)\left(\begin{array}{c}
u_{2(m+1)} \\
u_{2(m+1)+1} \\
u_{r(m)} \\
w_{2(m+1)} \\
W_{2(m+1)+1} \\
w_{r(m)} \\
\theta_{2(m+1)} \\
\theta_{2(m+1)+1} \\
\theta_{r(m)}
\end{array}\right)
$$

14 Nevertheless, this initial model can be improved by removing the $n$ last nodes of the rigid 15 body. Each node $r(m)$ is free from both prescribed displacements and applied external forces. In other words, the applied nodal forces according to the $x$-axis and to the $y$-axis as well as the nodal moment according to the z-axis are equal to zero. As a result, 3

18 linear combinations involving only DoF are obtained. It allows then for the elimination of the 3 DoF associated to the remaining node $r(m)$, leading to the following relationship between the vector of nodal forces and the vector of nodal displacements: 
$\left(\begin{array}{c}Q_{2(m+1)} \\ Q_{2(m+1)+1} \\ R_{2(m+1)} \\ R_{2(m+1)+1} \\ S_{2(m+1)} \\ S_{2(m+1)+1}\end{array}\right)=\left(\begin{array}{cccccc}\frac{2 C_{u} C_{\theta}}{C} & -\frac{2 C_{u} C_{\theta}}{C} & 0 & 0 & h \frac{C_{u} C_{\theta}}{C} & h \frac{C_{u} C_{\theta}}{C} \\ -\frac{2 C_{u} C_{\theta}}{C} & \frac{2 C_{u} C_{\theta}}{C} & 0 & 0 & -h \frac{C_{u} C_{\theta}}{C} & -h \frac{C_{u} C_{\theta}}{C} \\ 0 & 0 & C_{w} & -C_{w} & 0 & 0 \\ 0 & 0 & -C_{w} & C_{w} & 0 & 0 \\ h \frac{C_{u} C_{\theta}}{C} & -h \frac{C_{u} C_{\theta}}{C} & 0 & 0 & \frac{2 C_{\theta}^{2}+h^{2} C_{u} C_{\theta}}{C} & -\frac{2 C_{\theta}^{2}}{C} \\ h \frac{C_{u} C_{\theta}}{C} & -h \frac{C_{u} C_{\theta}}{C} & 0 & 0 & -\frac{2 C_{\theta}^{2}}{C} & \frac{2 C_{\theta}^{2}+h^{2} C_{u} C_{\theta}}{C}\end{array}\right)\left(\begin{array}{c}u_{2(m+1)} \\ u_{2(m+1)+1} \\ W_{2(m+1)} \\ W_{2(m+1)+1} \\ \theta_{2(m+1)} \\ \theta_{2(m+1)+1}\end{array}\right)$

2 where:

$3 \quad C=2 C_{\theta}+\frac{h^{2} C_{u}}{2}$

4 In the case of a linear stress analysis of a single-lap bonded joint, only one macro5 element along the overlap is needed. The addition of fasteners for the linear stress 6 analysis of a single-lap HBB joint required both additional macro-elements and additional nodes, according to the former model (Paroissien 2007). Following the model presented in this paper, only additional macro-elements are required. To address a non-linear analysis of a single-lap bonded joint, the overlap can be meshed with several macroelements (Paroissien 2013a, Paroissien 2013b, Lélias 2015). As a result, the non-linear

11 analysis of a single-lap HBB joint can potentially involve the same number of macroelements and nodes as the non-linear analysis of the single-lap bonded joint obtained from the HBB configuration after removing the fasteners. In such a case, similar computational time can be expected. Finally, it is indicated that the same analysis can be easily conducted assuming spring stiffnesses on the upper side different from those of the lower side.

This paper does not focus on the computation of these fastener stiffnesses. Several papers address this topic and provide formulae, mainly semi-empirical, to assess these stiffnesses. Formulae for the shear stiffnesses can be found in (Tate 1946, Swift 1984, Huth 1986) for example. Simulating the fasteners as beams subjected to combined shear

21 and bending loading, both shear and bending fastener stiffnesses can be assessed (Cope 2000). This assessment makes use of a calibration with the semi-empirical Swift's formulae (Swift 1984). Following this last approach, the bending stiffness can be simply 
1 expressed as a function of the shear stiffness (Paroissien 2006, Paroissien 2007), such

2 as:

$3 \quad \frac{C_{\theta}}{C_{u}}=\frac{3}{8}\left(1+v_{f}\right) \phi^{2}$

4 where $v_{f}$ is the Poisson's ratio of the fastener and $\phi$ the fastener diameter. Finally, the fastener stiffness according to the $y$-axis can be computed as the axial tensile stiffness:

$6 \quad C_{w}=\frac{E_{f} \pi \phi^{2}}{4 h}$

$7 \quad$ where $E_{f}$ is the Young's modulus of the fastener.

8 Finally, it is indicated that the present approach offers the abilities to consider various

9 calibration of fastener stiffnesses to be representatives for dedicated local behaviour 10 around the fastener (Bois 2013).

\subsection{RESOLUTION}

13 Assuming a pure linear analysis of a single-lap HBB joint with $n$ fasteners, the model is 14 then composed by $n+1$ BB elements, $n$ fastening elements and 2 beam elements. The stiffness matrix of the joint is then assembled according to the classical assembly rules of the FE method. A total number of $2 n+6$ nodes then $6 n+18$ DoF is then involved. In order to consider non linear materials, an iterative procedure based on an adaptation of the Newton-Raphson algorithm is developed (Lélias 2015). Contrary to the linear elastic case for which only one BB element is required for an entire bonded bay, the $n+1$ bonded bays have to be meshed. Various displacements or forces can be applied to the suitable nodes. The vector of nodal displacements is then obtained, allowing for the computation for each macro-element of twelve integration constants and then the building of displacement, force and stress distributions within the joint. Furthermore, the bolt load transfer rates are computed from the normal forces in the adherends. The validation of this model is complicated, since the results are dependent of the assumed fastener flexibilities. However, when restricted to HBB joints with similar isotropic linear elastic adherends, the present model provides the same results as those by Paroissien et al. 
1 (Paroissien 2007). Besides, the present model is able to address the pure bonded joints,

2 for which elements of validation and of assessment against refined FE models are 3 provided in (Paroissien 2013a, Paroissien 2013b, Lélias 2015). A simple comparison with

4 the Goland and Reissner's theory (Goland 1944) is provided in this paper. The 5 mechanical and geometrical parameters under consideration are given in Table 1. For this configuration the moment factor computed through Goland and Reissner's theory is equal to 0.6671 . To perform the exact comparison, the model is then simply adapted by choosing the length outside the overlap, which provides this same moment factor. The comparison of the adhesive shear and peeling stresses obtained with the previous models are given in Figure 5 and Figure 6. It is shown that, when the present model is employed under the same hypotheses as those of Goland and Reissner's theory, it provides the same results.

\section{FIRST APPLICATION EXAMPLES ON UNBALANCED CONFIGURATION}

In order to illustrate the use of the presented model, unbalanced single-lap bonded and HBB joints in-plane loaded are analyzed. For the presented application, the single-lap HBB joint differs from the single-lap bonded joint, in terms of geometrical and mechanical parameters, only by the presence of bolts. The geometry of joints under consideration is illustrated in Figure 7, while the geometrical and mechanical parameters are given in Table 2 and Table 3 respectively. The upper adherend (adherend 1) is a

21 laminated material. The layup is quasi-isotropic according to [-45/45/0/90/0/-45/45/90]s and the mechanical parameters of the lamina are extracted from (Kelly 2006). The lower adherend (adherend 2) is isotropic. The adherends have neither the same thickness nor the same stiffnesses. In this section, the materials are assumed to be linear. The joints are assumed to be clamped at one extremity and free to move at the other extremity in the x-direction only.

27 Considering the HBB joint, the influence of the adhesive Coulomb's modulus on the load carried out by each of both bolts is provided in Figure 8. As the adherends are geometrically and mechanically dissimilar, both bolt load transfer rates are different. The 
1 bolt load transferred is obtained by subtracting the values of normal forces in the lower 2 adherend at the fastener location. The bolt load transfer rate is obtained by dividing the 3 bolt load transferred by the applied tensile load. Moreover, it appears that the bolt 4 transfer rates decrease very rapidly to zero with the increase of the adhesive stiffness. 5 The adhesive modulus range, which allows for a significant load transferred by both the fasteners and the adhesive layer, is then restricted to adhesives having low modulus. In term of load transfer, the mechanical behaviour of HBB joints tends to be the same as that of bonded joints when structural adhesives are used. Exactly the same tendencies are obtained, if the relative adhesive shear stiffness $G / e$ is varying instead of the

10 adhesive shear modulus $G$. Comparing to a pure bolted configuration, the adhesive layer of the HBB configuration allows for the unloading of holes, so that the significance of potential benefit in fatigue strength is dependent on the fatigue strength of the adhesive 13 layer.

14 In order for both fasteners to transfer a part of the applied load, a low adhesive modulus is employed (see Table 3). The nearest fastener to the clamped end is transferring $7.56 \%$ of the applied load while the other fastener is transferring $7.17 \%$ of the applied load. The adhesive stress distributions along the overlap have similar evolutions for both configurations (Figure 9 and Figure 10). In terms of stress level, the adhesive peel stress distributions are very similar for both configurations, whereas the adhesive shear stress 20 is clearly reduced for the HBB configuration compared to that of pure bonded 21 configuration. This reduction of the adhesive shear stress level along the overlap is related to the reduction of the load transferred by the adhesive layer, from which the 23 load carried by the fasteners is removed. In terms of maximal adhesive stress values, 24 the difference on peel peaks between both configurations is not significant, whereas the adhesive shear peak for the HBB configuration is relatively different from $-6.34 \%$ from that of the pure bonded configuration. The variation of the difference in the adhesive 27 shear peak for the HBB configuration relatively to that of pure bonded configuration as a function of the adhesive Coulomb's modulus is provided in Figure 11. It is shown that 
1 this difference tends to zero when the adhesive Coulomb's modulus increases. However,

2 a significant reduction remains for higher adhesive modulus.

3 Besides, the normal forces, shear forces and bending moments in the lower adherends is

4 presented in Figure 12 to Figure 14. The influence of fastener contribution within the

5 internal equilibrium of HBB joints clearly appears through discontinuities at fastener

6 locations ( 0.25 and 0.75 in terms of normalized abscissa along the overlap). For a given

7 adhesive, the level of these discontinuities is a function of fastener stiffnesses as shown

8 in Figure 8 . The slope of the normal (shear) forces curve is representative for the

9 adhesive shear (peel) stress. The influence of fasteners in the reduction of stress

10 gradients is then clearly highlighted. It appears that the variation of the shear forces and

11 bending moment is not monotonic along the overlap, contrary to the normal forces.

12 However, the model is able to retrieve this distribution along the overlap with one macro-

13 element only. The prediction of internal loads offers the possibility, for example, to use

14 this model to compute strength criteria based on Linear Fracture Mechanics (Fraisse 15 1993).

\section{ANALYSIS OF A QUASI-STATIC TEST}

Thanks to experimental and numerical tests, this section aims at investigating the mechanical behaviour of a single-lap HBB joint, made of metallic adherends, under quasistatic loading. The experimental and numerical tests are presented. In addition of the

21 1D-beam test, the numerical test includes predictions from a 3D FE model. It is indicated that the selected material laws and associated material parameters used for the

23 numerical tests are chosen according to the own judgment of the authors after several 24 trial tests. It is not claimed that the choice is optimal.

\subsection{EXPERIMENTAL TEST}

\subsubsection{Manufacturing of Specimen}


1 The specimen is assembled from an aluminium alloy 2024-T351 plate using six

2 countersunk head fasteners and an adhesive layer to implement a single bonded/bolted 3 overlap joint configuration. The geometry of the joint configuration is shown in Figure 15.

4 A methacrylate adhesive from the LORD Corporation is used. The fastening system is 5 composed of titanium alloy TA6V screws with a shank diameter of $5.56 \mathrm{~mm}$ (prEN6114V-3A-4) and of steel nuts (ASNA2531-3A). Before joining, the plates are drilled. The diameter of each hole is calibrated with regards to the actual shank diameters with a tolerance of $\pm 10 \mu \mathrm{m}$. On one plate, the screws are installed in the holes. On the other plate, the adhesive is applied under the shape of only one bead between both fastener rows. Both plates are then joined and the nuts are tightened on wet adhesive layer,

11 before the beginning of its polymerization. In particular, the adhesive layer thickness is 12 not calibrated.

\subsubsection{Experimental set up}

A hydraulic $250 \mathrm{kN}$ Instron tensile machine is used, for which a displacement controlled loading at a rate of $1 \mathrm{~mm} / \mathrm{min}$ is applied. The specimen was clamped on tabs with 17 hydraulic grips.

A full field displacement measurement VIC 3D (Digital Image Correlation System) is introduced and placed in front of each sample on the bolt area; experimentally a random pattern with good contrast was applied to the surface of specimen, countersunk face specimen. A calibration process, performed before loadings, allows to establish the precise position of the two cameras, relative to each other and to the specimen. Displacement, load, strain sensors and 3D field measurement, were recorded simultaneously with a $10 \mathrm{~Hz}$ (1 Hz for 3D camera) frequency rate and stored.

\subsection{NUMERICAL TEST}

27 Finite element analyses are achieved with the FE software ABAQUS Standard, version 14-

28 3. On the basis of a set of hypotheses, the main objective is to make a comparison of the 29 3D FE model with the experimental results and the 1D-beam model for global and local 
1 behavior of HBB joints. The relative performances of predictions from both models are not discussed in this paper. A detailed comparison of predictions from FE models and from the present 1D-beam model is provided in (Lélias 2015) on the end notched flexure, double cantilever beam, mixed mode bending and single-lap bonded specimen involving cohesive zone modeling. The FE modeling of the bolting part is based on the own knowhow of authors as published in (Paroissien 2006, Hoang-Ngoc 2010, Lachaud 2011, Sola 2016) applied in the frame of a standard use of ABAQUS software. The full set of hypotheses employed for each of both models is then described in the next section allowing for the reproducibility of this study.

\subsubsection{D FE MODEL}

Mesh and boundary conditions (see Figure 16). The 3D FE model makes use of quadratic brick elements (C3D20) under normal integration scheme. Three elements in the thickness of each plate are set and a mesh refinement was used near the hole in each adherend. Three boundary conditions remain unchanged throughout the analysis. Clamped regions are used on each end of the sample. Prescribed displacements are applied by a reference point linked with nodes of adherend part. Displacement boundary conditions are placed along the specimen in order to take into account symmetric conditions ( $1 / 3$ of the specimen is modelled). Before applying the displacement load, a preload of 6,000 $\mathrm{N}$ is applied on each bolt with a specific load case, through the standard preload methodology by Abaqus Software. The diameter clearance between bolt and adherend is $0.02 \mathrm{~mm}$.

23 Standard penalty contact conditions with 0.3 friction value are applied between each adherend, and between the adherends and the bolts. Cohesive contact conditions with cohesive behavior are introduced between each adherend on the overlap part. The cohesive behavior is described hereafter.

27 Material Behaviors. The 3D FE model described below used non linear behavior laws for each material as summarized in Table 4. For each adherend, made in aluminium alloy, an 
1 elastic perfectly plastic isotropic behavior is used. Same behavior is used for the screw

2 made in titanium alloy. Linear elastic behavior is used for steel nut.

3 The cohesive behavior law, for adhesive progressive failure modelling, is described in

4 Figure 17. A classical bi-linear cohesive damage behavior model implemented in ABAQUS

56.14 is used. Damage initiation is realized by a quadratic stresses criterion and failure appearance with the Benzeggagh-Kenane (BK) energetic criterion. Stiffness coefficients are given according to the adhesive thickness and bulk modulus (see Table 4).

Benzeggagh-Kenane parameter describing the mixed mode coupling is taken equal to one (Benzeggagh 1996). This 3D model uses behavior laws close to those used in the 1D-beam model described in section 4.2.2.

Computation. The computation used Full Newton Raphson solver (ABAQUS General Standard) with nonlinear geometric activation. The full Newton Raphson scheme involved an update of the tangent stiffness matrix at each iteration; this scheme appears to the authors as a suitable approach to support the progressive failure of the adhesive layer. Moreover, the classical viscous regularization is activated with the related couple of parameters $\tau=1 \mathrm{E}-4 \mathrm{~s}$ and $\mathrm{a}=1$ (Allix 2003, Sola 2016). It allows in particular for a better convergence within implicit scheme. The damage evolutions predicted by the 3D FE model have an exponential shape and appears as more progressive than those predicted by the 1D-beam model. It can be related to the effect of the activation of the viscous regularization in the 3D FE model.

\subsubsection{D-BEAM MODEL}

23 Mesh and boundary conditions. The 1D-beam model described in section 2 is used by 24 including non linear behavior laws for the adhesive and the fasteners. In order to support non linear material behavior of the adhesive layer, a non linear computation procedure is implemented as described in (Lélias 2015); it is based on Newton Raphson making use of

27 the secant stiffness matrix with an update of the stiffness matrix at each iteration. A number of 56 macro-elements (one macro-element per millimeter) is set. As for the 3D 
1 FE model, the specimen is clamped at one extremity and free to move at the other

2 extremity in the longitudinal direction only where the load is applied.

3 Material Behaviors. The adherends are assumed to be linear elastic with the same 4 characteristics (see Table 4). A bilinear law is assumed for the fastener stiffness along 5 the $x$-direction $\left(C_{u}\right)$, involving then 3 material parameters, listed in Table 5. Both other fastener stiffnesses $\left(C_{u}\right.$ and $\left.C_{w}\right)$ are computed from equation (10) and (11). For the adhesive layer, an interface model following (Allix 1996) is implemented under the shape of a simple bilinear damage evolution law. Linear energetic criterion for both initiation and propagation are then employed, involving 5 parameters provided in Table 6 . Because of the wet installation of fasteners, the adhesive thickness varies along the overlap area.

11 The hypothesis of a constant adhesive thickness in the macro-element appears as a restriction in its use. However, it is possible to represent the adhesive thickness variation by meshing with macro-elements having its own constant thickness. By assuming the continuity of adhesive stresses at macro-elements boundaries, linear relationships between the degrees of freedom appear. The use of a reduction matrix allows then for the management of the offset of neutral lines induced by the variation of adhesive thickness, similarly to the former approach to link fasteners to the model. Nevertheless, in this paper, there is no attempt to represent the actual local adhesive thickness along the overlap and a fixed cohesive law is assumed.

\subsection{ANALYSIS OF RESULTS}

\subsubsection{Global behaviour of the HBB joint}

23 The curves of force as a function of the total displacement for the experimental test, the 1D-beam test and the 3D FE test are provided in Figure 18. The force is normalized by the force of the first peak, experimentally measured. All results are normalized to this same maximum load.

27 The experimental test shows a linear behavior up to the first force peak at around a total displacement of $1.25 \mathrm{~mm}$. The load loss is around $8 \%$. After this first drop, the load is recovered up to the second force peak at a normalized force of around 1.05 and a total 
1 displacement of around $1.6 \mathrm{~mm}$. The load loss for this second peak is around $36 \%$. The

2 load is then recovered exhibiting a bilinear behavior up to a normalized force of 1.03 and

3 a total displacement of around $2.5 \mathrm{~mm}$, point for which the six fasteners fail in shear.

4 In order to validate the 3D FE model, the experimental and numerical displacement fields on the overlap for both fasteners of the central rows are compared in Figure 19 at a total displacement of the specimen equal to $0.65 \mathrm{~mm}$. The scale factor is the same between both pictures. It is then shown that the field displacement given by the 3D FE model is close to experimental results.

\subsubsection{Failure mechanism kinematic}

After a comparison of the global mechanical behavior as measured by experimental test and as predicted by $1 \mathrm{D}$-beam and 3D FE tests, the current section shows the local analysis of the damage initiation and propagation within the adhesive layer of the HBB

14 joint. It is indicated that the good agreement obtained at the global scale is not sufficient to validate the ability of the $1 \mathrm{D}$-beam model to describe the actual local damaging process.

Both numerical tests predict a progressive damage evolution from damage initiation to failure propagation in the adhesive starting at both extremities of the overlap in direction of the middle of the overlap. For both 1D-beam and 3D FE tests, the prediction of the damage evolution in the adhesive layer was monitored on the 3 particular points: $A, B$ and $\mathrm{C}$. The points $\mathrm{A}$ and $\mathrm{B}$ are located at both extremities of the overlap, with $\mathrm{A}$ located on the clamping side and $B$ at the other side. The point $C$ is located in the middle of the overlap. The results are provided in Figure 20 as a function of the total displacement of the specimen and superimposed on the normalized force measured during the experimental test. As the 1D-beam model assumes a perfectly symmetrical joint, the damage evolution at the point $A$ and point $B$ are similar. On the contrary, the $3 \mathrm{D} \mathrm{FE}$ model is representative for the dissymmetry of the joint inherent to the fastening system. The 3D FE test predicts then an initiation of the damage at the point $A$ then at the point $B$. Indeed, the point $A$ is located near the clamped side. But, the clamped 
1 adherend contains the countersunk heads of bolts, which clearly contributes less in terms

2 of stiffness than the other adherend linked to the nut. The damage evolutions predicted

3 by the 3D FE model appear as more progressive than those predicted by the 1D-beam

4 model. It can be related to the activation of the viscous regularization in the 3D FE

5 model.

6 The 3D field measurement pictures show the same results as the 3D FE model 7 predictions, so that the later can help to detect failure mechanism (see Figure 19). In 8 Figure 21, the measured normal strain field as well as the measured out-of-plane 9 displacement field is presented, before and after the first peak load (see Figure 18).

10 In Figure 21 a, first line bolt is not loaded because adhesive is not failed. The blue zone in 11 front of this bolt line indicates the bending of the plate just before the overlap part. This zone disappears after the first load peak because of the adhesive layer failure, which leads to the release of the bending moment into tensile strain. The bending zone appears then in Figure $21 \mathrm{~b}$ on the first bolt line because the bending moment is shifted. This dissymmetrical failure of the adhesive zone on edge distances, localized on the plate including the countersunk head fasteners, induces an out-of-plate displacement jump. The out-of-plane displacement changes from $1.2 \mathrm{~mm}$ to $1.6 \mathrm{~mm}$ between both pictures (see Figure 21a, Figure 21b).

The second peak load is investigated in Figure 20. The successive load loss is associated to the total failure of adhesive zone (damage equal to 1 on point $\mathrm{C}$ ). Both numerical 21 models are very close to each other. The damage value increases very rapidly for both numerical models. In this case, only the fasteners transfer the load since the adhesive 23 has entirely failed. The pictures from the 3D field measurement also show the final failure 24 of the adhesive zone between both fastener lines. In Figure 22, the normal measured strain field as well as the out of plane measured displacement field, before and after the second peak load (see Figure 18).

27 The measured strain and displacement fields shown in Figure 22a are close to the ones 28 shown in Figure 21b, particularly concerning the dissymmetrical adhesive failure. In Figure 22b, the measured strain field is shown, when the total failure of the adhesive 
1 appears or equivalently when the damage in the center of the overlap (point $\mathrm{C}$ of Figure

220 ) is equal to 1 . Only the six bolts are then loaded which indicates the total failure of 3 the adhesive.

4 A damage indicator over a characteristic area is defined as the sum of damage parameters divided by the maximal possible value of this sum. Two characteristic lengths are monitored: (i) both overlap edges and (ii) the length between the fasteners. Each characteristic area has a length of $28 \mathrm{~mm}$. As shown in Figure 23, the damage initiates on both edge distances. This damage remains constant up to the first force peak. The first load loss appears linked to fast damage propagation. During the first load recovery, the damage propagation goes on up to the complete failure of the adhesive layer on both edge distances. Then the damage initiates between the fasteners and grows up to the second force peak. The second load loss is associated to the complete failure of the adhesive layer between the fasteners. As a result at this stage, only the fasteners are loaded up to the final failure of the specimen. According to the numerical tests, it can be concluded that the failure mechanism of the HBB joint tested is driven by the progressive damage evolution within the adhesive layer. Moreover, the damage evolution seems to concern firstly the edge distances only and then the area between both fasteners, once the adhesive is failed over the entire edge distance. Both numerical tests provide almost this same tendency. However, the 3D FE model allows for a light damage initiation between the fasteners before the entire failure 21 of the adhesive on both edge distances.

\section{CONCLUSION}

24 A simplified model for the stress analysis of single-lap HBB joints is presented in this paper. This model is based on the macro-element technique. It supports non linear adhesive and fastener material behaviours as well as unbalanced configurations involving composite and metallic adherends. The output of this model is the distribution of forces and displacements in the adherends and in the fasteners as well as the distributions of adhesive shear and peel stresses along the overlap. This model can address both 
1 boundary cases: the pure bonded joints and the pure bolted joints. A simplification of the

2 fastening simulation is presented.

3 It is shown that the model is able to predict the quasi-static mechanical behaviour up to 4 failure of HBB joints, experimentally measured. The resulting identified failure mechanisms correspond to the ones already observed. The failure is initiated at overlap ends in the adhesive layer and propagated toward the first fasteners. If only one fastener is employed, the load is then carried out by this fastener, similarly to a pure bolted joint. If two fasteners are present, the adhesive failure propagates between the fasteners up to the middle of the overlap; the fasteners carry then the loads, similarly to a pure bolted joint. The progressive degradation of the adhesive layer results in the increase of the bolt

11 load transfer rate, so that the HBB joints considered progressively pass from a nearly pure bonded joint behaviour to a pure bolted joint behaviour. Besides, the predictions by the 1D-beam test on pure bonded and pure bolted configurations are given in Figure 24, using the same set of geometrical and mechanical parameters as the one already used for HBB configurations. The same boundary conditions are used. This test allows for the comparison of predicted mechanical performance under quasi-static loading. For the case under study, it reveals that the HBB joint offers higher strength and stiffness. The mechanical performance of the pure bonded and HBB configuration are closed. However, the fasteners in the HBB configuration allows for the delay of the final failure of the joint as well as a lightly higher maximal load capacity.

21 The present model takes benefits of the flexibility of the FE method, so that various geometrical configurations can be addressed, through simple manipulations on the stiffness matrix. This model could be used in the aim of a design optimization approach. For example, the predictions by the $1 \mathrm{D}$-beam test on the initial configurations and a new configuration are given in Figure 25. The new configuration is based on the same singlelap joint geometry with squared end. The same materials are involved. The differences with the initial configuration are the width (30 mm instead of $28 \mathrm{~mm}$ ), the thickness (2 $\mathrm{mm}$ instead of $2.5 \mathrm{~mm}$ ), the length of the overlap (60 mm instead of $58 \mathrm{~mm}$ ) and the length outside the overlap ( $110 \mathrm{~mm}$ instead of $112 \mathrm{~mm}$ ). The fasteners are moved so 
1 that their abscissa remains at $25 \%$ and $75 \%$ of the overlap length. The volume of 2 adherend materials related to the new configuration is $12 \%$ smaller than the one of the 3 initial configuration, while the first peak load is $10 \%$ higher. This conclusion holds if the

4 adherends remain in its elastic domain at this load level. Besides, this model could be used for the identification of material laws and associated parameters of fastener stiffness as well as adhesive layers. In particular, the presented approach is able to numerically test specimen relevant to Fracture Mechanics (Lélias 2015) for the identification of cohesive damage laws. The development performed on the bonded-beam element to consider thermal loadings (Paroissien 2013b) can be applied to the HBB configuration. The further developments of the present simplified analysis will target the

11 consideration of non linear geometries as well as of fatigue analysis based on progressive damage propagation (Khoramishad 2011, Lachaud 2011).

\section{ACKNOWLEDGMENT}

The authors affiliated to Sogeti High Tech gratefully acknowledge the engineers and the managers involved in the development of JoSAT (Joint Stress Analysis Tool) internal research program led by Sogeti High Tech. Both first authors sincerely acknowledge Denis Campassens (Airbus Group) for the providing of test specimen.

\section{REFERENCES}

21 (Allix 1996) $O$ Allix and $P$ Ladevèze. Damage mechanics of interfacial media: Basic aspects, identification and application to delamination. Damage and Interfacial

23 Debonding in Composites, Studies in Applied Mechanics, 44, Eds. Allen D. and Voyiadjis 24 G., Elsevier, 167-88 (1996)

(Allix 2003) O Allix, P Feissel, P. Thevenet. A delay damage mesomodel of laminates

27 under dynamic loading: basic aspects and identification issues. Computers and Structures, vol. 81, 1177-1191 (2003) 
1 (Bigwood 1989) DA Bigwood and AD Crocombe. Elastic analysis and engineering design

2 formulae for bonded joints. International Journal of Adhesion and Adhesives. Vol. 9, No.

34 (1989).

4

5 (Benzeggagh 1996) ML Benzeggagh and $M$ Kenane. Measurement of Mixed-Mode Delamination Fracture. Toughness of Unidirectional Glass/Epoxy Composites with MixedMode Bending Apparatus. Composites Science and Technology, Vol. 56, pp. 439-449, (1996)

(Bois 2013) C Bois, H Wargnier, JC Wahl, E Le Goff. An analytical model for the strength 11 prediction of hybrid (bolted/bonded). Composite Structures, Vol. 97, pp. 252-260 (2013). 12

13 (Chowdhury 2015) N Chowdhury, WK Chiu, J Wang, P Chang. Static and fatigue testing 14 thin riveted, bonded and hybrid fiber double lap joints used in aircraft structures. Composite Structures, Vol. 121, pp. 315-323 (2016).

(Cope 2000) DA Cope, TE Lacy. Stress intensity determination in lap joints with mechanical fasteners. Proceedings of 41st AIAA/ASME/ASCE/AHS/ASC Structures, Structural Dynamics, and Materials conference, AIAA-2000-1368, 3-6 April 2000, Atlanta, GA (2000).

(Fraise 1993) P Fraisse and F Schmit. Use of J-integral as fracture parameter in simplified analysis of bonded joints. International journal of Fracture, Vol. 63, pp, 59-73 (1993)

(Fu 2001) M Fu, PK Mallick. Fatigue of hybrid (adhesive/bolted) joints in SRIM (2001). 
1 (Goland 1944) M Goland, E Reissner. The stresses in cemented joints. Journal of Applied 2 Mechanics, Vol. 11, pp. A17-27 (1944).

3

4 (Hartman 1966) A Hartman. Fatigue tests on single lap joints in clad 2024-T3 aluminium 5 6 7

(Hoang-Ngoc 2010) CT Hoang-Ngoc, E Paroissien. Simulation of single-lap bonded and hybrid (bolted/bonded) joints with flexible adhesive. International Journal of Adhesion and Adhesives, Vol. 30, pp. 117-129 (2010).

(Högberg 2004) JL Högberg. Mechanical behaviour of single-layer adhesive joints. Thesis for the degree of licentiate of engineering, Chalmers University of Technology, Göteborg, Sweden (2004).

(Huth 1986) $\mathrm{H}$ Huth. Influence of Fastener flexibility on the prediction of load transfer and fatigue life for multiple row joints. Fatigue in mechanically fastened composite and metallic joints, ASTM STP 927, John M. Potter, Ed., Philadelphia, PA, pp. 221-250 (1986). (Imanaka 1995) M Imanaka, K Haraga, T Nishikawa. Fatigue strength of adhesive/rivet combined lap joint. Journal of Adhesion, Vol. 49, pp. 197-209 (1995).

(Kelly 2006) G Kelly. Quasi-static strength and fatigue life of hybrid (bonded/bolted) composite single-lap joints. Journal of Composite Structures, Vol. 72, pp. 119-129 (2006). 
1 (Khoramishad 2011) H Khoramishad, AD Crocombe, KB Katnam, IA ASHCROFT. Fatigue

2 damage modelling of adhesively bonded joints under variable amplitude loading using a

3 cohesive zone model. Engineering Fracture Mechanics, Vol. 78, Issue 18, pp. 3212-3225

4 (2011)

5

6 (Kumar 2010) B Kumar, CT Sun, PH Wang, R Sterkenburg. Adding Additional Load Paths 7 in a Bonded/Bolted Hybrid Joint. Journal of Aircraft, Vol. 47, No. 5, pp. 1593-1598 8 (2010).

9

10 (Lachaud 2011) F Lachaud. Contribution à I'analyse multi échelle du comportement 11 mécanique non linéaire matériau des structures composites. HDR Thesis (in French) 12 Institut de Génie Mécanique, Université Toulouse III - Paul Sabatier, France (2011)

13 http://oatao.univ-toulouse.fr/5165/1/lachaud 5165 hdr.pdf [access in March 2017]

(Lélias 2015) G Lélias, E Paroissien, F Lachaud, J Morlier, S Schwartz, C Gavoille. An extended semi-analytical formulation for fast and reliable stress analysis of adhesively

17 bonded joints. International Journal of Solids and Structures. Vol. 62 (2015), pp. 18-39

(Mortensen 2002) F. Mortensen, OT Thomsen. Analysis of adhesive bonded joints: a unified approach. Composite Science and Technology, Vol. 62, pp. 1011-1031 (2002).

(Oterkus 2007) E Oterkus, A Barut, E Madenci, DR Ambur. Analysis of bolted-bonded 23 composite lap joints. Proceedings of $48^{\text {th }}$ AIAA/ASME/ASCE/AHS/ASC Structures, 24 Structural Dynamics, and Materials Conference, AIAA-2007-2187, 23-26 April 2007, 25 Honolulu, Hawaii.

27 (Paroissien 2006) E Paroissien. Contribution aux assemblages hybrides 28 (boulonnés/collés) - Application aux jonctions aéronautiques. PhD Dissertation (in 
1 French), Institut de Génie Mécanique, Université Toulouse III - Paul Sabatier, France (2006) http://thesesups.ups-tlse.fr/3/1/Paroissien Eric.pdf [access in March 2017]

4 (Paroissien 2007) E Paroissien, M Sartor, J Huet, F Lachaud. Analytical two-dimensional model of a hybrid (bolted/bonded) single-lap joint. AIAA Journal of Aircraft, ISSN 00218669, Vol. 44, n², pp. 573-582 (2007).

7

8 (Paroissien 2013a). E Paroissien, F Gaubert, A Da Veiga and F Lachaud. Elasto-Plastic Analysis of Bonded Joints Using Macro-Elements. Journal of Adhesion and Science

10 Technology, pp. 1464-1498 (2013).

(Paroissien 2013b). E Paroissien, F Lachaud, and T Jacobs. A simplified stress analysis of bonded joints using macro-elements. In: Advanced in Modeling and Design of Adhesively Bonded Systems. S Kumar and KL Mittal (Eds.), Scrivener Publishing, Wiley, pp. 93-146 (2013).

(Raju 2016). KP Raju, K Bodjona, GH Lim, L Lessard. Improving load sharing in hybrid bonded/bolted composite joints using interference-fit bolt. Composite Structures, Vol. 149, pp. 329-338 (2016).

(Samaei 2016). M Samaei, M Zehsaz, TN Chakherlou. Experimental and numerical study of fatigue crack growth of aluminium 2024-T3 single lap simple bolted and hybrid

23 (adhesive/bolted) joints. Engineering Failure Analysis. Vol. 59, pp. 253-268 (2016)

(Sola 2016) C Sola, B Castanié, L Michel, F Lachaud, A. Delabie and E Mermoz. On the 26 role of kinking in the bearing failure of composite laminates. Composite Structures. 141, 184-193 (2016). 
1 (Stapelton 2012). SE Stapleton. The analysis of adhesively bonded advanced composite

2 joints using joint finite elements. PhD thesis. University of Michigan (2012).

3

4 (Swift 1984) T Swift. Fracture analysis of stiffened structure, Damage Tolerance of 5

$$
\left\{\begin{array}{l}
\frac{d^{6} S}{d x^{6}}-k_{1} \frac{d^{4} S}{d x^{4}}+k_{4} \frac{d^{2} S}{d x^{2}}+S\left(k_{2} k_{3}-k_{1} k_{4}\right)=0 \\
\frac{d}{d x}\left(\frac{d^{6} T}{d x^{6}}-k_{1} \frac{d^{4} T}{d x^{4}}+k_{4} \frac{d^{2} T}{d x^{2}}+T\left(k_{2} k_{3}-k_{1} k_{4}\right)\right)=0
\end{array}\right.
$$

(Weissgraeber 2014). P Weissgraeber, N Stein and W Becker. A general sandwich-type model for adhesive joints with composite adherends. International Journal of Adhesion and Adhesives, Vol. 55, pp. 56-63 (2014).

(Williams 1975). JH Williams. Stresses in adhesive between dissimilar adherends. International Journal of Adhesison and Adhesives. (1975).

APPENDICES A. Summarizing the resolution scheme for the BB element formulation.

From the governing equations (1)-(3), the system of differential equations in adhesive stresses can be uncoupled:

and solved such as:

$\left\{\begin{array}{l}S(x)=\left[\begin{array}{l}\overline{K_{1}} e^{s x} \sin (t x)+\overline{K_{2}} e^{s x} \cos (t x)+\overline{K_{3}} e^{-s x} \sin (t x) \\ +\overline{K_{4}} e^{-s x} \cos (t x)+\overline{K_{5}} e^{r x}+\overline{K_{6}} e^{-r x}\end{array}\right] \\ T(x)=\left[\begin{array}{l}K_{1} e^{s x} \sin (t x)+K_{2} e^{s x} \cos (t x)+K_{3} e^{-s x} \sin (t x) \\ +K_{4} e^{-s x} \cos (t x)+K_{5} e^{r x}+K_{6} e^{-r x}+K_{7}\end{array}\right]\end{array}\right.$ 
1 where $K_{j}$ and $\overline{K_{j}}$ are integration constants, $r, s$ and $t$ are real numbers (roots of

2 characteristics equation from Cardan's method) and:

$3 \quad k_{1}=\frac{G b}{e}\left[\frac{D_{1}}{\Delta_{1}}\left(1+\frac{A_{1} e_{1}^{2}}{4 D_{1}}\right)+\frac{D_{2}}{\Delta_{2}}\left(1+\frac{A_{2} e_{2}^{2}}{4 D_{2}}\right)+\left(\frac{e_{1} B_{1}}{\Delta_{1}}-\frac{e_{2} B_{2}}{\Delta_{2}}\right)\right]$

$4 \quad k_{2}=\frac{G b}{e}\left[\frac{e_{1} A_{1}}{2 \Delta_{1}}-\frac{e_{2} A_{2}}{2 \Delta_{2}}+\left(\frac{B_{1}}{\Delta_{1}}+\frac{B_{2}}{\Delta_{2}}\right)\right]$

$5 \quad k_{3}=\frac{E b}{e}\left[\frac{e_{1} A_{1}}{2 \Delta_{1}}-\frac{e_{2} A_{2}}{2 \Delta_{2}}+\left(\frac{B_{1}}{\Delta_{1}}+\frac{B_{2}}{\Delta_{2}}\right)\right]$

$6 \quad k_{4}=\frac{E b}{e}\left[\frac{A_{1}}{\Delta_{1}}+\frac{A_{2}}{\Delta_{2}}\right]$

$7 \quad \Delta_{j}=A_{j} D_{j}-B_{j}^{2} \neq 0, j=1,2$

8 The displacements in the adherends are then expressed as functions of the adhesive

9 stresses, their derivatives and polynomial expressions. The forces in the adherends are

10 then deduced from the adherend constitutive equations (1). The determination of the

11 twelve independent integration constants is performed thanks to the work by Högberg

12 (Högberg 2004). The nodal displacements and the nodal forces can be then obtained as

13 functions of this set of integration constants:

$14 \quad U=\left(\begin{array}{c}u_{i} \\ u_{j} \\ u_{k} \\ u_{l} \\ w_{i} \\ w_{j} \\ w_{k} \\ w_{l} \\ \theta_{i} \\ \theta_{j} \\ \theta_{k} \\ \theta_{l}\end{array}\right)=\left(\begin{array}{c}u_{1}(0) \\ u_{2}(0) \\ u_{1}(\Delta) \\ u_{2}(\Delta) \\ w_{1}(0) \\ w_{2}(0) \\ w_{1}(\Delta) \\ w_{2}(\Delta) \\ \theta_{1}(0) \\ \theta_{2}(0) \\ \theta_{1}(\Delta) \\ \theta_{2}(\Delta)\end{array}\right)=M C \quad$ and $\quad F=\left(\begin{array}{c}Q_{i} \\ Q_{j} \\ Q_{k} \\ Q_{1} \\ R_{i} \\ R_{j} \\ R_{k} \\ R_{l} \\ S_{i} \\ S_{j} \\ S_{k} \\ S_{l}\end{array}\right)=\left(\begin{array}{c}-N_{1}(0) \\ -N_{2}(0) \\ N_{1}(\Delta) \\ N_{2}(\Delta) \\ -V_{1}(0) \\ -V_{2}(0) \\ V_{1}(\Delta) \\ V_{2}(\Delta) \\ -M_{1}(0) \\ -M_{2}(0) \\ M_{1}(\Delta) \\ M_{2}(\Delta)\end{array}\right)=N C$

15 where $Q, R$ and $S$ respectively refer to the nodal normal forces, shearing forces and

16 bending moments acting on the $\mathrm{BB}$ element. But, considering the expression for the 17 vector of nodal forces $(F)$ as a function of the vector of integration constants $(C)$ as well 
1 as the vector $C$ as a function of the vector of nodal displacements $(U)$, the stiffness

2 matrix of the BB element can be computed as follows:

$3 \quad K=N M^{-1}$

4

5 APPENDICES B. Stiffness matrix of a beam element (Paroissien 2013a, Paroissien $62013 b)$.

7 The stiffness matrix of the beam element with coupling stiffness is obtained by

8 differentiating each nodal force by each nodal displacement, and is written in the basis

$9\left(\begin{array}{llllll}u_{i} & u_{j} & w_{i} & w_{j} & \theta_{i} & \theta_{j}\end{array}\right)$, such as:

$10 \quad K=\left(\begin{array}{cccccc}\frac{A}{l} & -\frac{A}{l} & 0 & 0 & -\frac{B}{l} & \frac{B}{l} \\ -\frac{A}{l} & \frac{A}{l} & 0 & 0 & \frac{B}{l} & -\frac{B}{l} \\ 0 & 0 & \frac{12}{l^{3}} \frac{\Delta}{A} & -\frac{12}{l^{3}} \frac{\Delta}{A} & \frac{6}{l^{2}} \frac{\Delta}{A} & \frac{6}{l^{2}} \frac{\Delta}{A} \\ 0 & 0 & -\frac{12}{l^{3}} \frac{\Delta}{A} & \frac{12}{l^{3}} \frac{\Delta}{A} & -\frac{6}{l^{2}} \frac{\Delta}{A} & -\frac{6}{l^{2}} \frac{\Delta}{A} \\ -\frac{B}{l} & \frac{B}{l} & \frac{6}{l^{2}} \frac{\Delta}{A} & -\frac{6}{l^{2}} \frac{\Delta}{A} & \frac{1}{l}\left(3 \frac{\Delta}{A}+D\right) & \frac{1}{l}\left(3 \frac{\Delta}{A}-D\right) \\ \frac{B}{l} & -\frac{B}{l} & \frac{6}{l^{2}} \frac{\Delta}{A} & -\frac{6}{l^{2}} \frac{\Delta}{A} & \frac{1}{l}\left(3 \frac{\Delta}{A}-D\right) & \frac{1}{l}\left(3 \frac{\Delta}{A}+D\right)\end{array}\right)$

11

12

13

14 
2 Figure 1. Meshing of an in-plane loaded and clamped single-lap HBB joint, with fasteners 3 for example. The adherends outside the overlap are simulated by beam elements 4 (element 6 and 7), and the fasteners by special fastening element (element 4 and 5).

5 Each bonded bay is simulated by a bonded-beams element (element 1, 2 and 3).

Figure 2. Bonded-beams element: a four-nodes macro-element with three degrees of

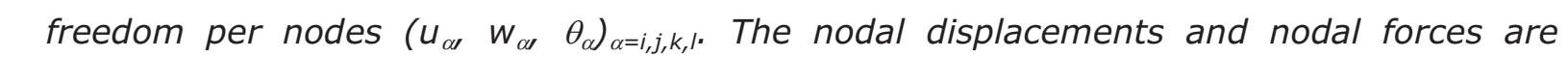
represented as well as the forces and the displacements in the adherends.

11 Figure 3. Free body diagrams of infinitesimal elements of the overlap.

Figure 4. A rigid body with the springs between the nodes $2(m+1)$ and $2(m+1)+1$ 14 simulating the fastener $m$.

Figure 5. Comparison of the shear stress distribution along the overlap provided by 17 Goland and Reissner's theory (1944) and the present model employed under the same assumptions.

Figure 6. Comparison of adhesive peeling stress distributions along the overlap provided 21 by Goland and Reissner's theory (1944) and the present model employed under the same assumptions.

Figure 7. Definition of the single-lap bonded and HBB joints under consideration.

Figure 8. Bolt load transfer rates of each of both bolts as functions of the adhesive

27 Coulomb's modulus for the single-lap HBB joint provided by the present model. 
1 Figure 9. Comparison of adhesive shear stress distributions along the overlap for the

2 single-lap bonded and HBB joints provided by the present model.

3

4 Figure 10. Comparison of adhesive peeling stress distributions along the overlap for the

Figure 17. Mixed-mode cohesive law model (Lélias 2015)

Figure 11. Relative difference in $\%$ of the adhesive shear peak for the HBB configuration relatively to the pure bonded configuration as functions of the adhesive Coulomb's modulus for the single-lap HBB joint provided by the present model.

Figure 12. Comparison of normal force distributions in the lower adherend (adherend 2) along the overlap for the single-lap bonded and HBB joints provided by the present model.

Figure 13. Comparison of shear force distributions in the lower adherend (adherend 2) along the overlap for the single-lap bonded and HBB joints provided by the present model.

Figure 14. Comparison of bending moment distributions in the lower adherend (adherend 2) along the overlap for the single-lap bonded and HBB joints provided by the present model.

Figure 15. Geometry of the specimen. Dimensions in $\mathrm{mm}$.

Figure 16. Mesh and boundary conditions of the 3D Finite Element model. 
1 Figure 18. Force displacement curves for the experimental test, the 1D-beam test and

2 the 3D FE test. The force is normalized by the first peak force experimentally measured.

3

4 Figure 19. Displacement field in the tensile direction on the overlap around the two

\section{Numerical 3D FE field.}

Figure 20. Evolution of damage parameter in point $A, B$ and $C$ according to the $1 D$-beam test and the 3D FE test. $A$ is located at the extremity of the overlap near from the clamped side. $B$ is located at the other extremity. $C$ is located in the middle of the overlap.

Figure 21. Strain along sample in tensile direction and out-of-plane displacement, around the first peak load (3D FE model).

Figure 22. Strain along sample in tensile direction and out-of-plane displacement, around the second peak load (3D FE model).

Figure 23. Evolution of damage indicator computed on both edge distances and between the fastener lines according to the 1D-beam test and the 3D FE test.

Figure 24. Force displacement curves for the experimental test on HBB joint and for the $1 D$-beam test on HBB, pure bonded and pure bolted joint. The force is normalized by the first peak force experimentally measured.

Figure 25. Force displacement curves for the 1D-beam test on HBB in the initial and new configurations. The force is normalized by the first peak force experimentally measured (initial configuration) 
2 Table 1. Geometrical and mechanical parameters for the single-lap bonded joint under 3 the configuration of Goland and Reissner's theory.

4

5 Table 2. Geometric parameters employed for the single-lap bonded and HBB joints.

6

7 Table 3. Mechanical parameters employed for the single-lap bonded and HBB joints.

8

9 Table 4. Material law and parameters assumed in the frame of the 3D FE model.

10

11 Table 5. Bilinear law assumed for the fasteners.

12

13 Table 6. Bilinear damage evolution law assumed for the adhesive layer.

14

15

16

17

18

19

20

21

22

23

24 


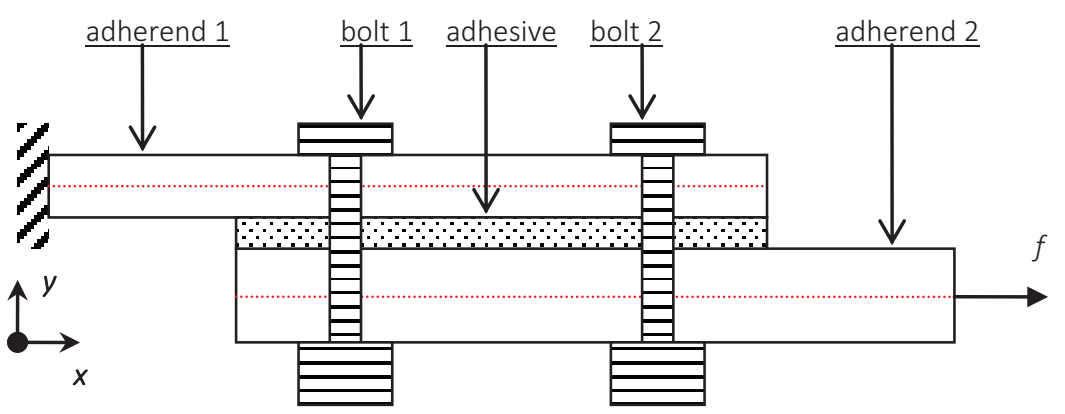

4

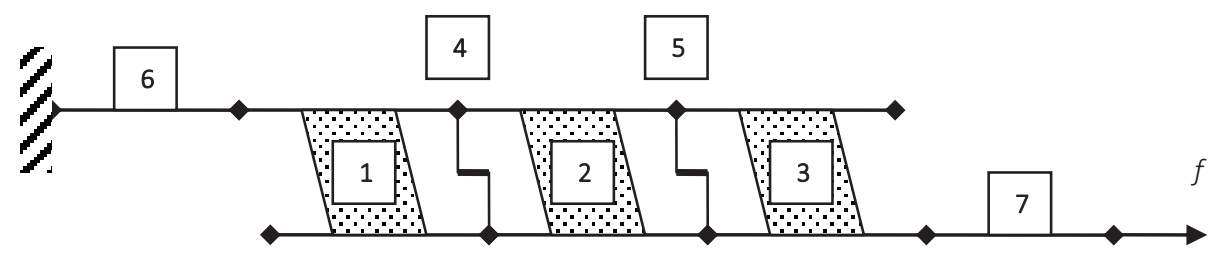

5

6 Figure 1. Meshing of an in-plane loaded and clamped single-lap HBB joint, with fasteners 7 for example. The adherends outside the overlap are simulated by beam elements 8 (element 6 and 7), and the fasteners by special fastening element (element 4 and 5).

9 Each bonded bay is simulated by a bonded-beams element (element 1, 2 and 3).
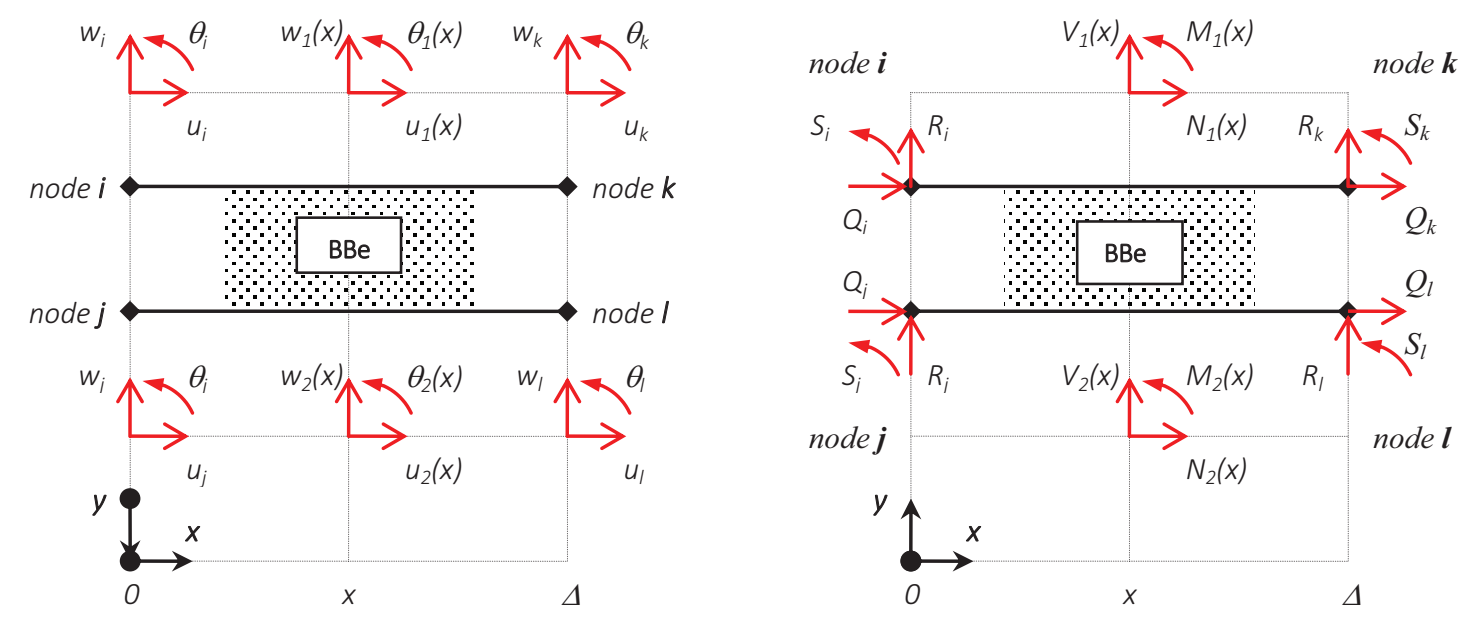
1 Figure 2. Bonded-beams element: a four-nodes macro-element with three degrees of

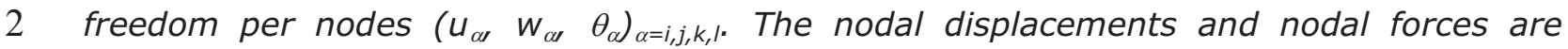
3 represented as well as the forces and the displacements in the adherends.
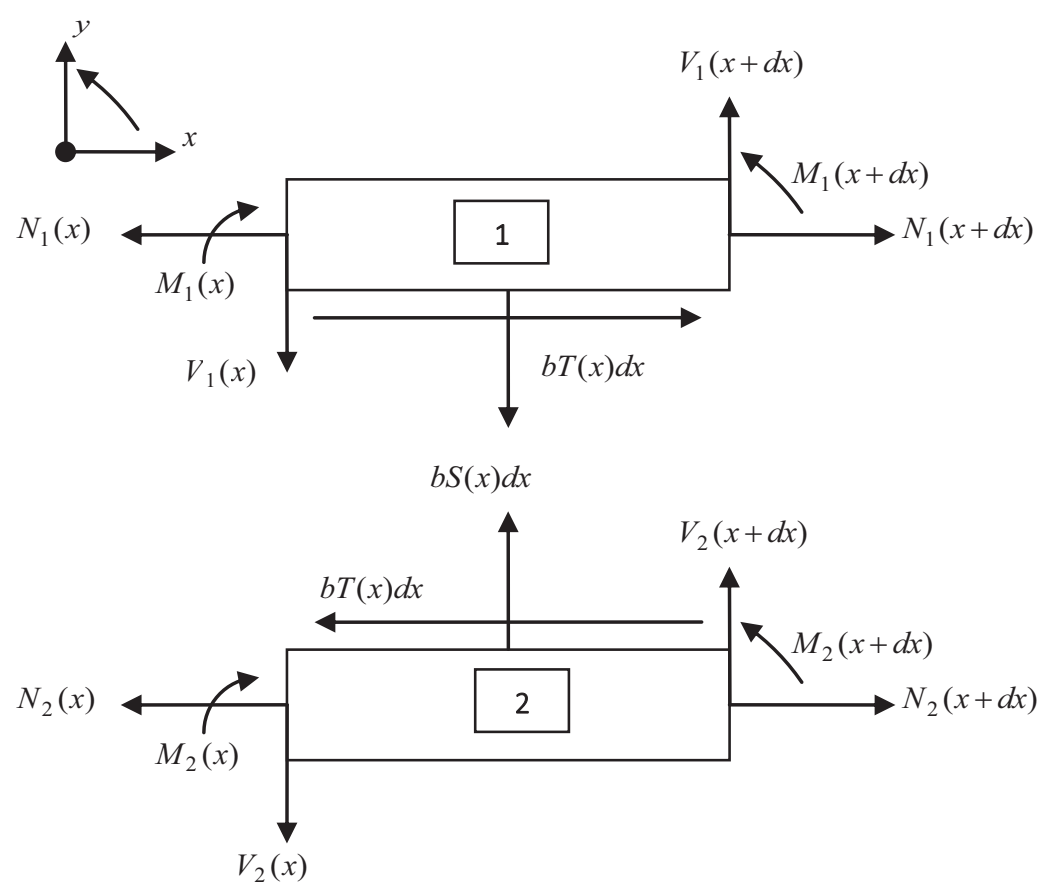

Figure 3. Free body diagrams of infinitesimal elements of the overlap.

7

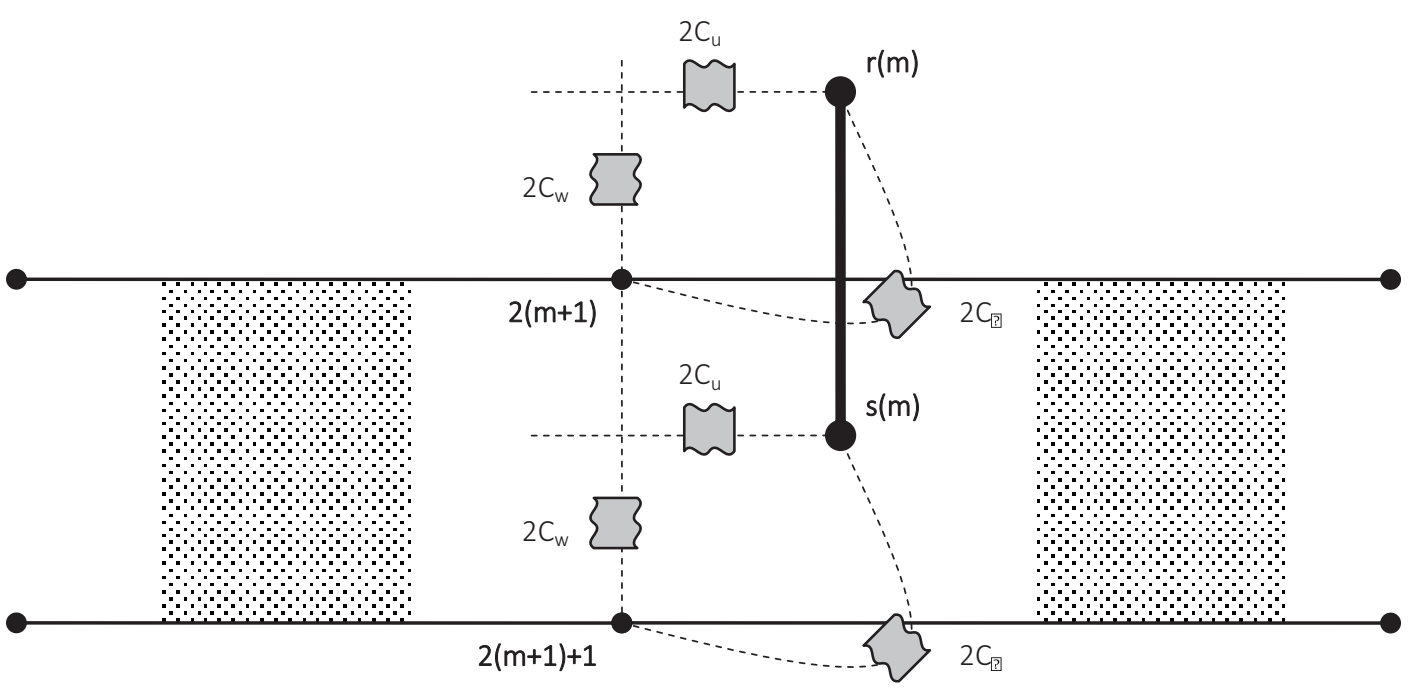

8

9 Figure 4. A rigid body with the springs between the nodes $2(m+1)$ and $2(m+1)+1$ simulating the fastener $m$. 


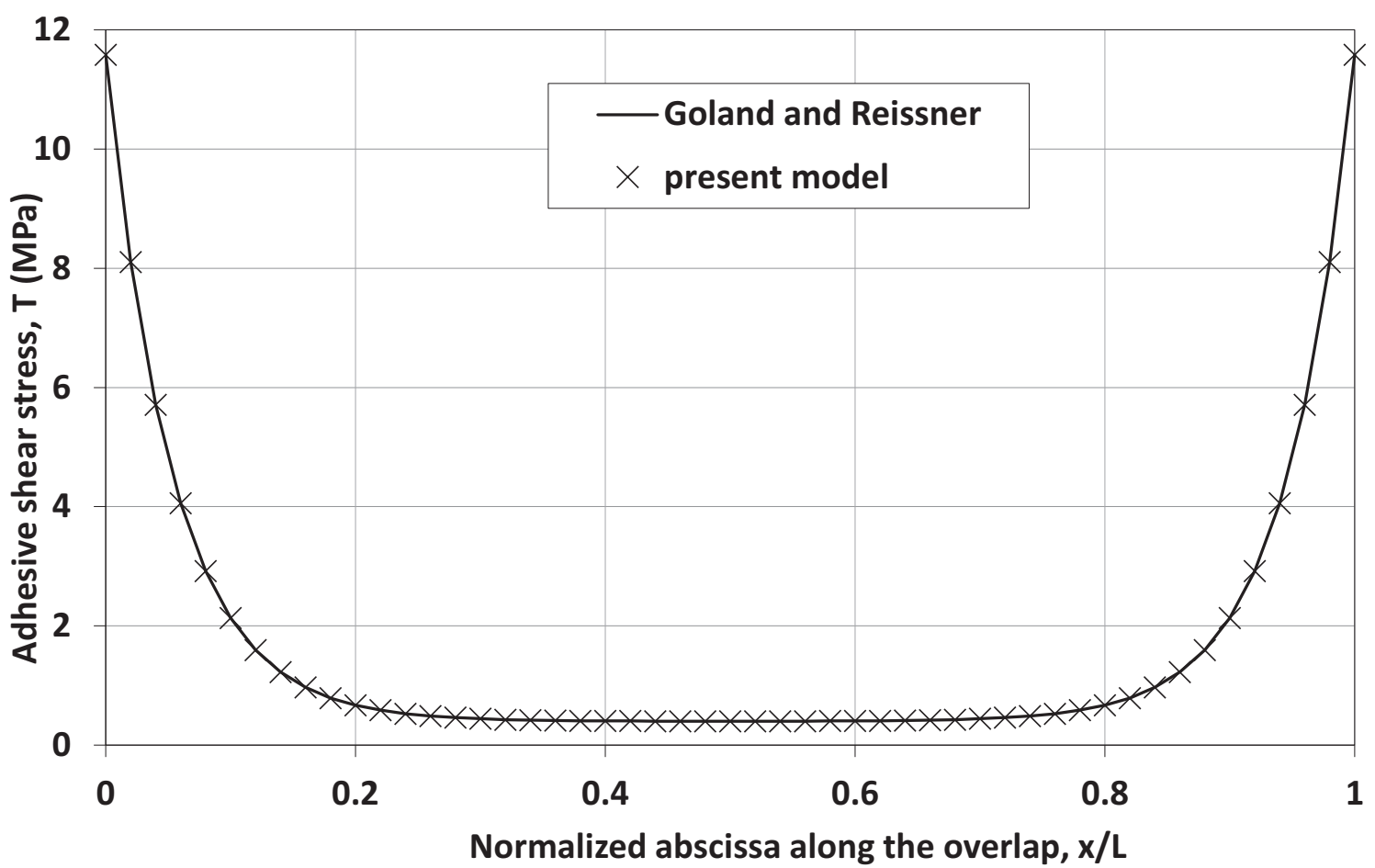

3

4 Figure 5. Comparison of the shear stress distribution along the overlap provided by 5 Goland and Reissner's theory (1944) and the present model employed under the same 6 assumptions

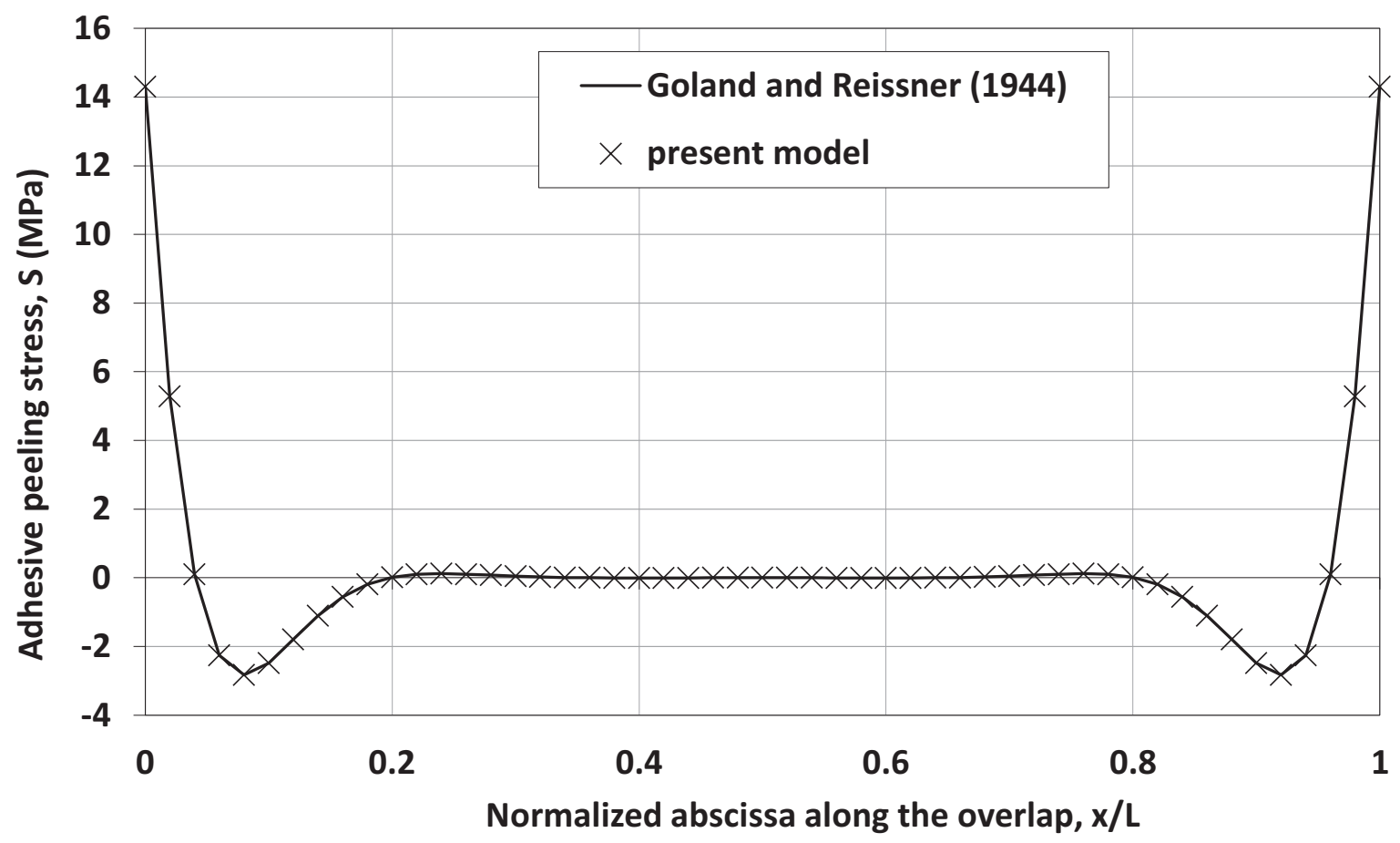


1 Figure 6. Comparison of adhesive peeling stress distributions along the overlap provided 2 by Goland and Reissner's theory (1944) and the present model employed under the same 3 assumptions.

4

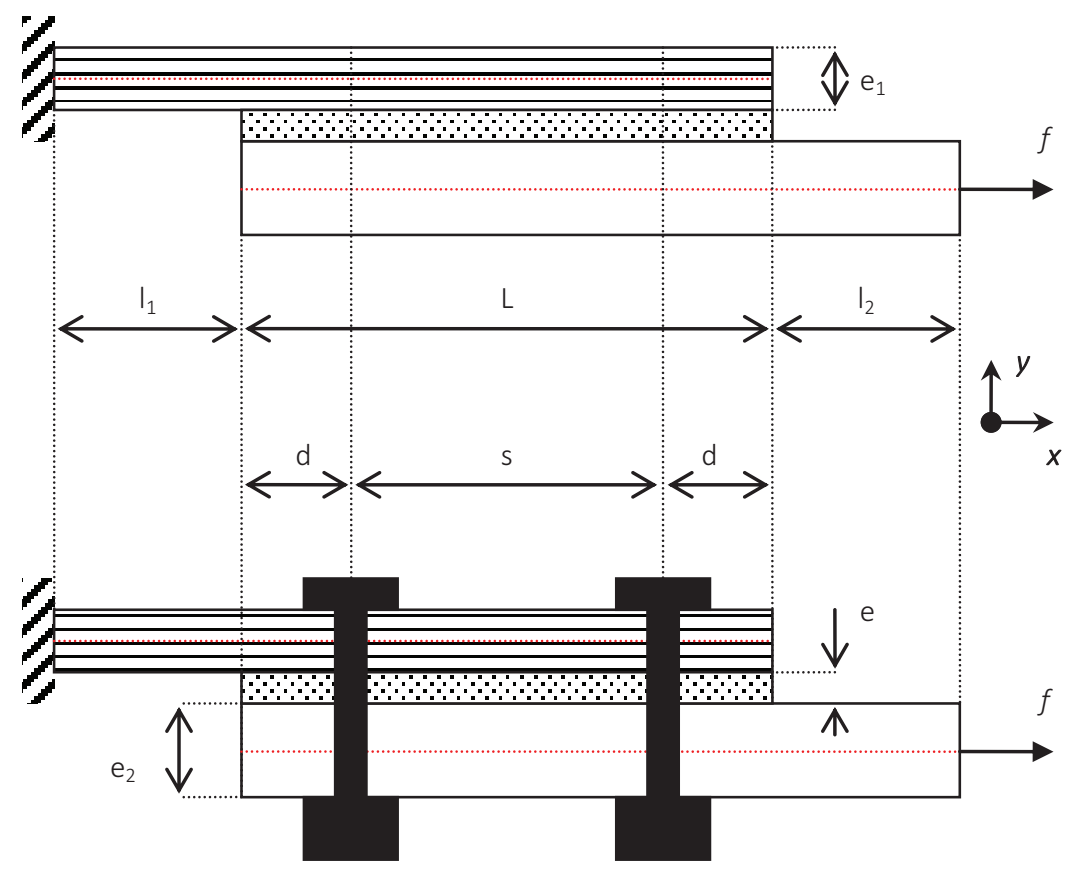

6

7 Figure 7. Definition of MCM single-lap bonded and HBB joints under consideration 


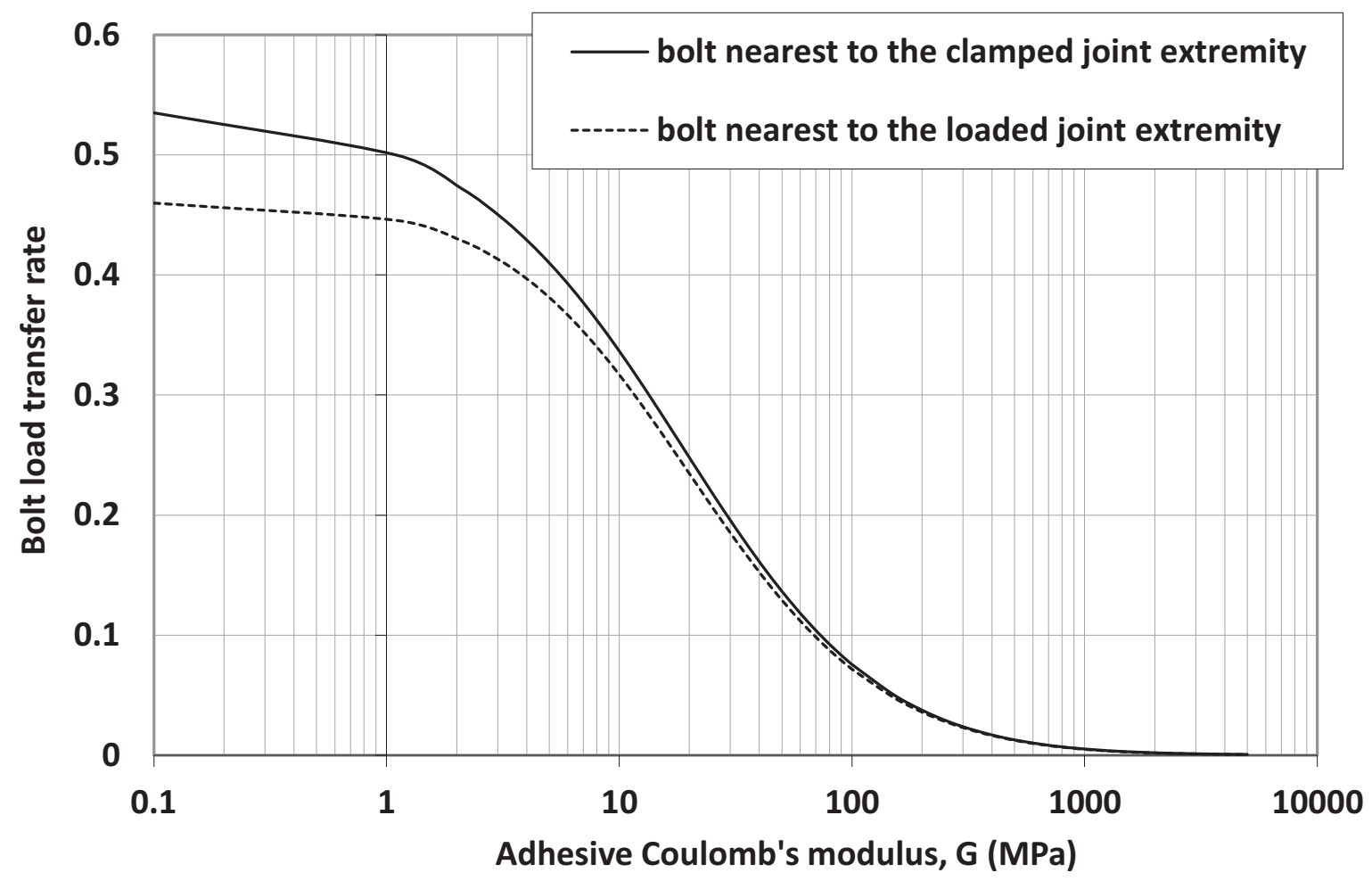

1

2 Figure 8. Bolt load transfer rates of each of both bolts as functions of the adhesive

3 Coulomb's modulus for the single-lap HBB joint provided by the present model

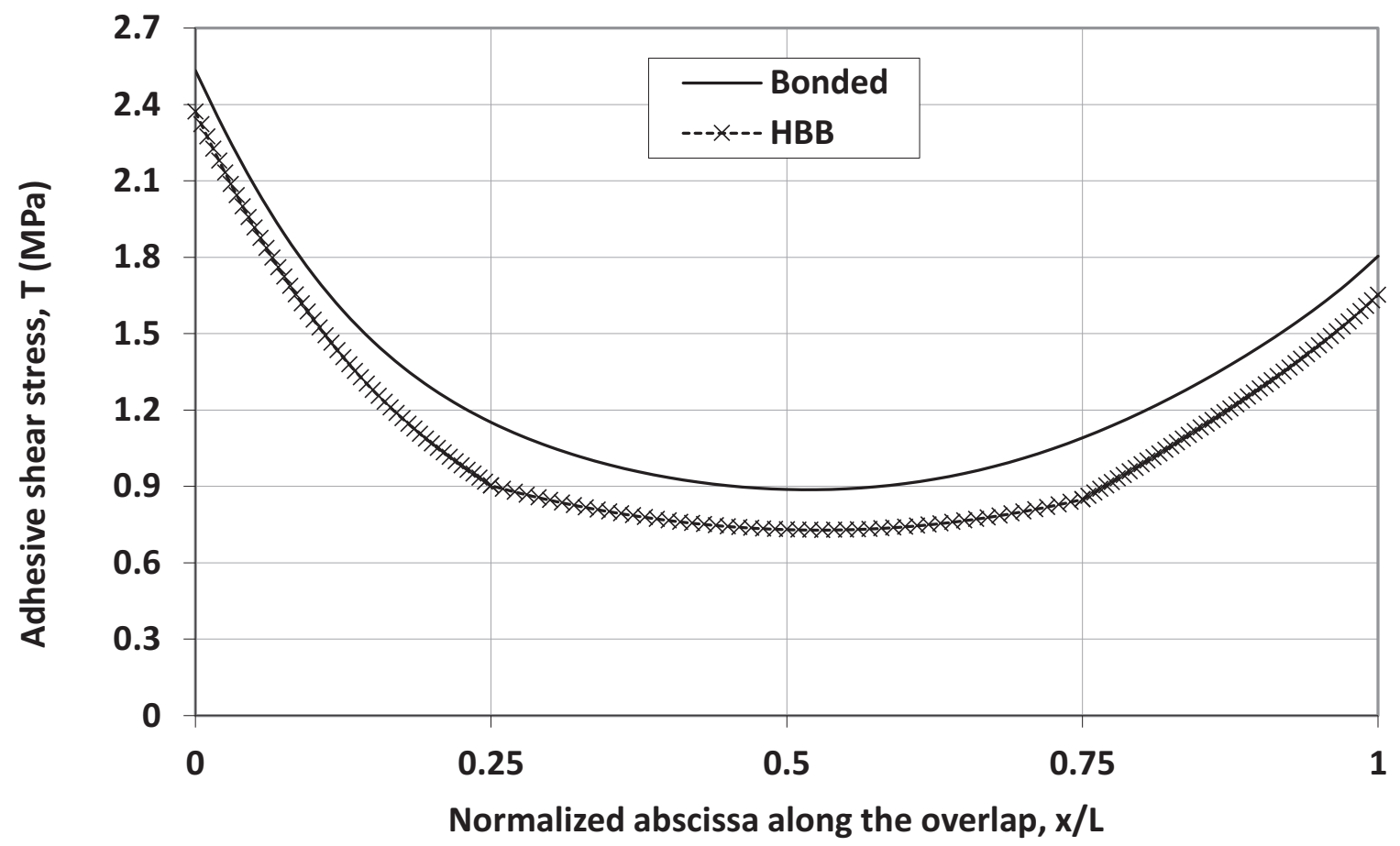

5 Figure 9. Comparison of adhesive shear stress distributions along the overlap for the 6 single-lap bonded and HBB joints provided by the present model 


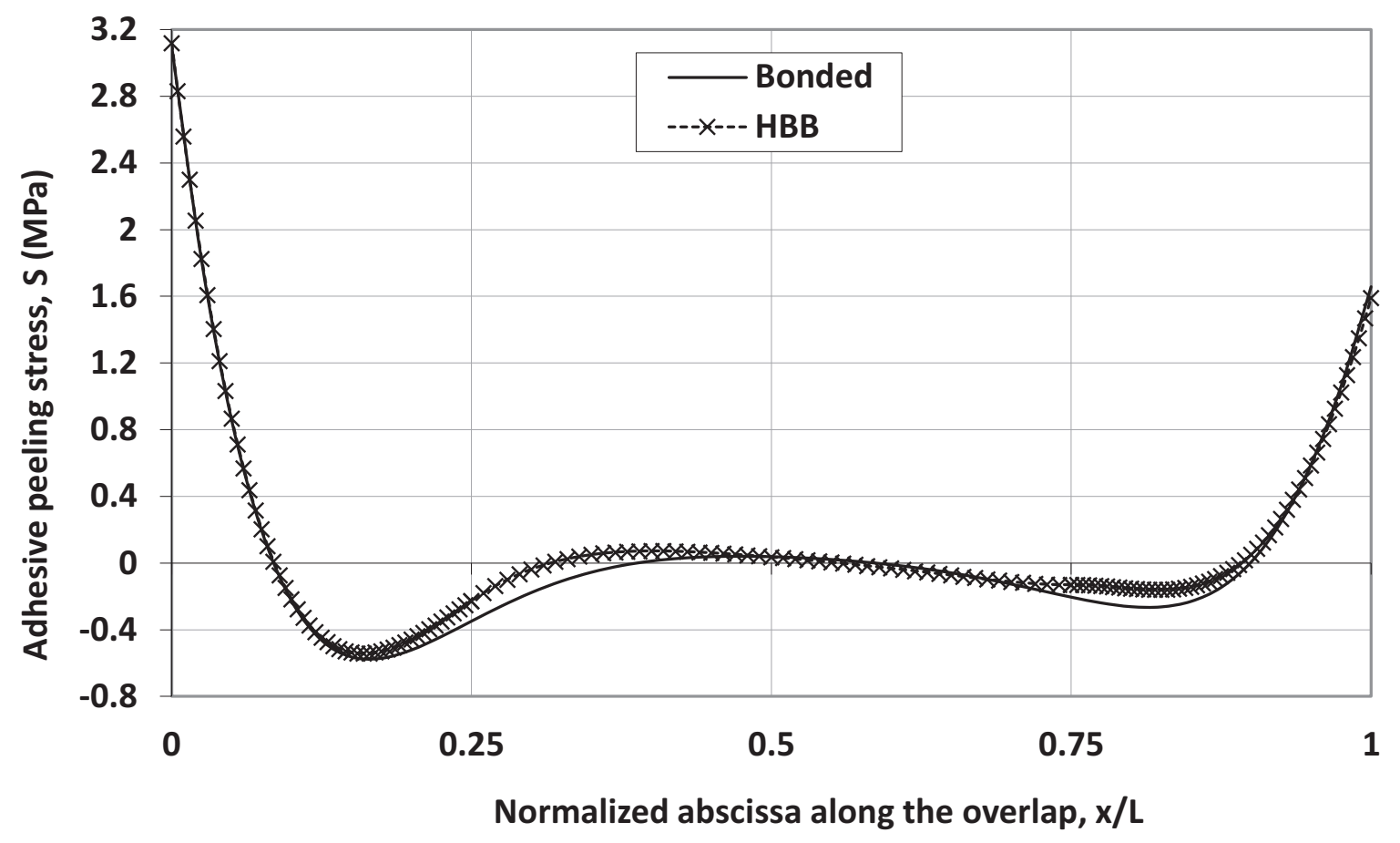

2 Figure 10. Comparison of adhesive peeling stress distributions along the overlap for the

3 single-lap bonded and HBB joints provided by the present model

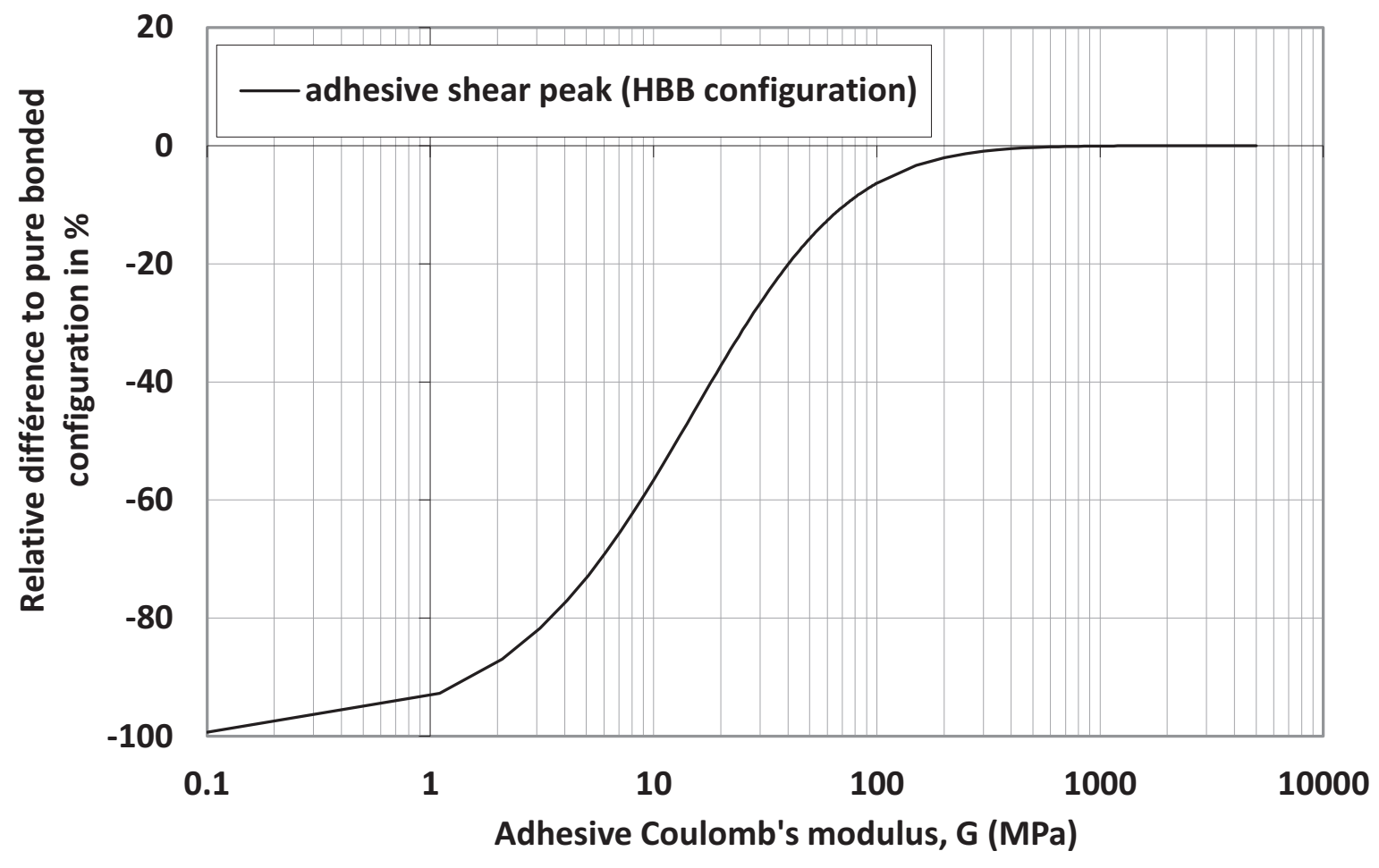


1 Figure 11. Relative difference in \% of the adhesive shear peak for the HBB configuration

2 relatively to the pure bonded configuration as functions of the adhesive Coulomb's

3 modulus for the single-lap HBB joint provided by the present model

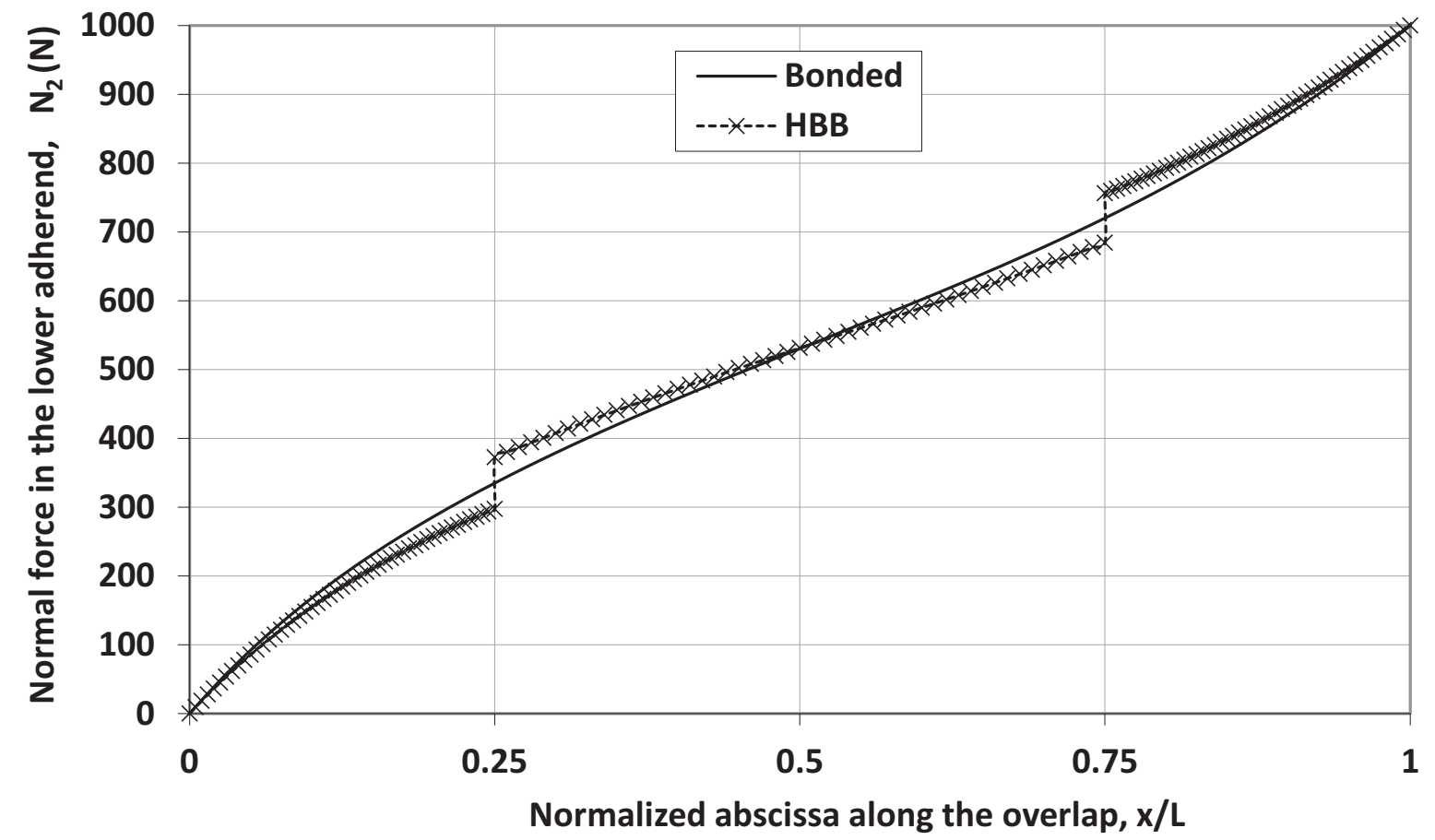

4

5 Figure 12. Comparison of normal force distributions in the lower adherend (adherend 2)

6 along the overlap for the single-lap bonded and HBB joints provided by the present 7 model

8 


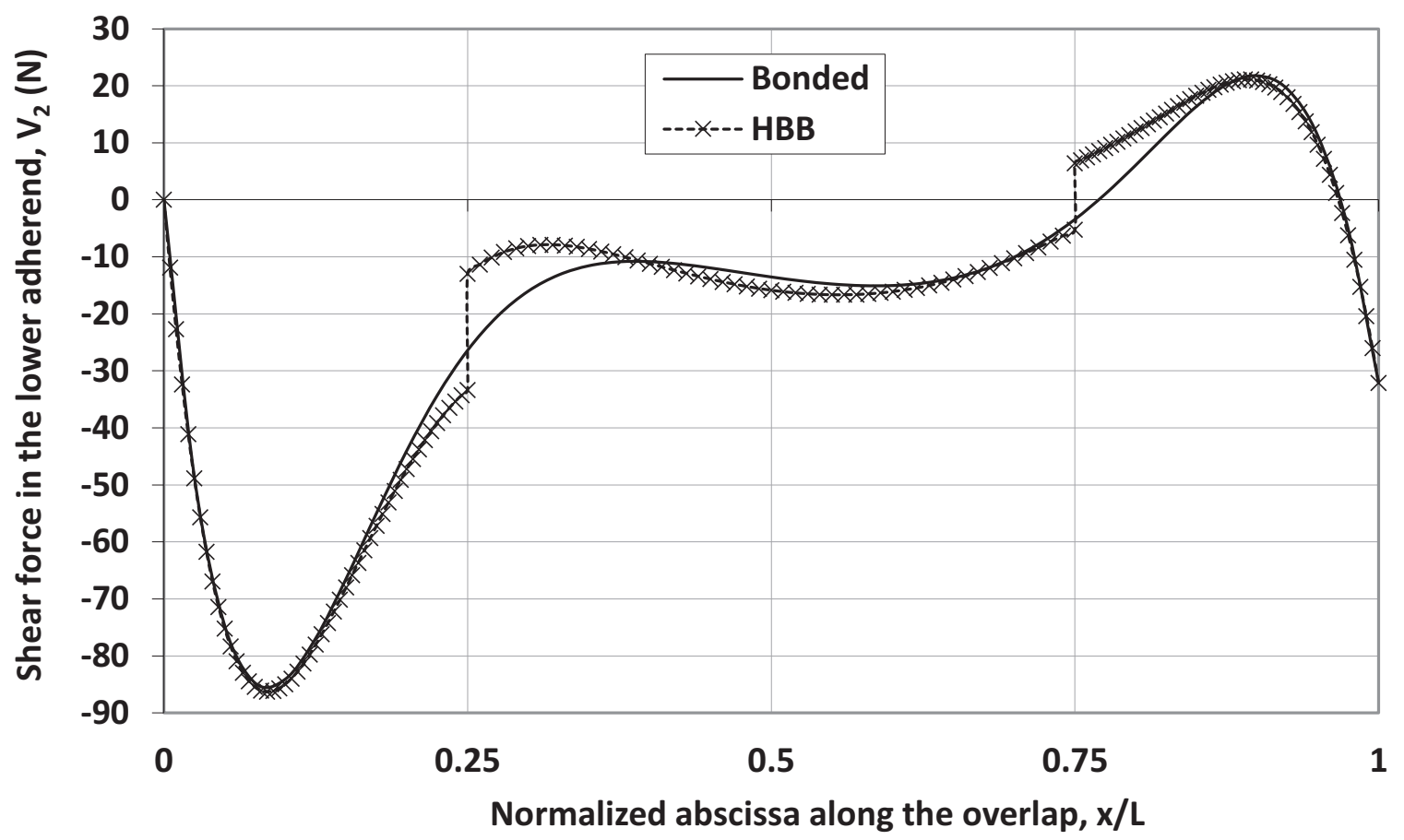

2 Figure 13. Comparison of shear force distributions in the lower adherend (adherend 2)

3 along the overlap for the single-lap bonded and HBB joints provided by the present 4 model

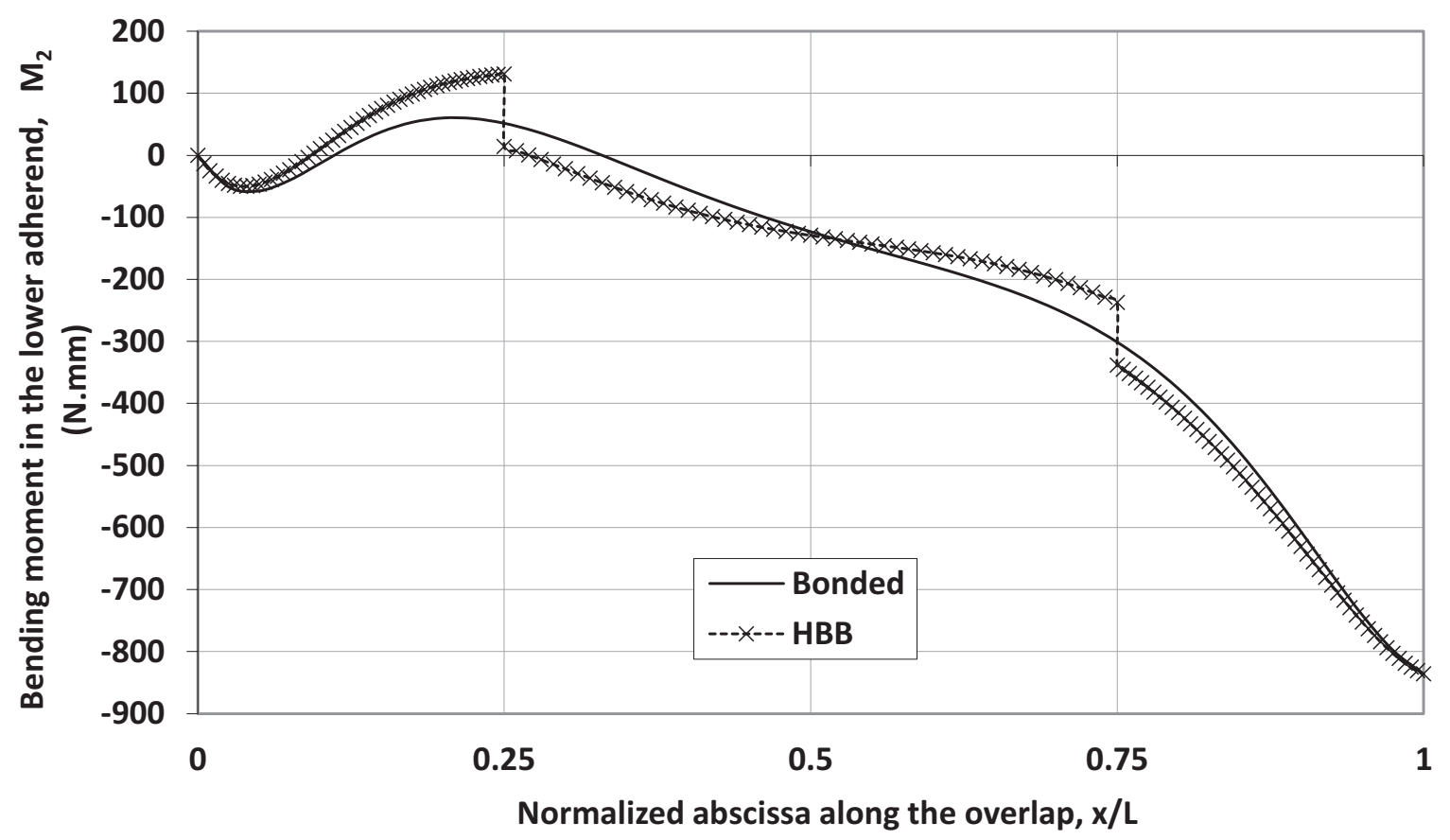


1 Figure 14. Comparison of bending moment distributions in the lower adherend (adherend

2 2) along the overlap for the single-lap bonded and HBB joints provided by the present 3 model

4

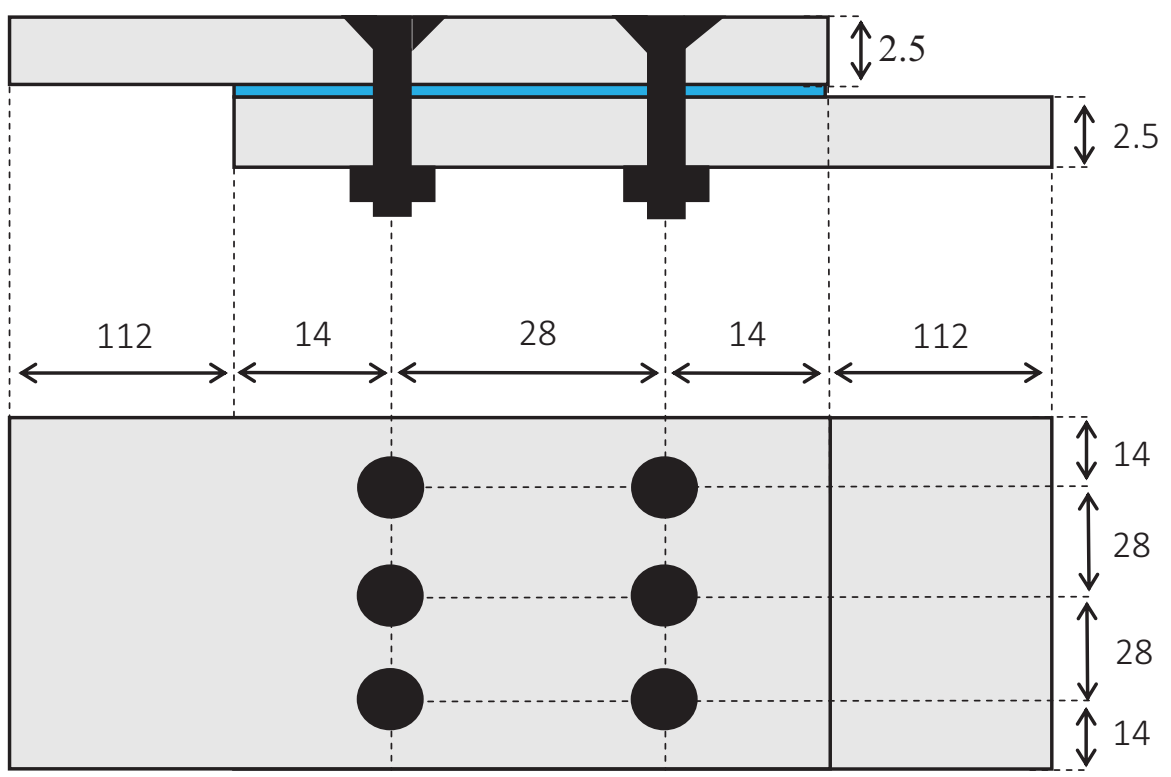

6 Figure 15. Geometry of the specimen. Dimensions in $\mathrm{mm}$.

7

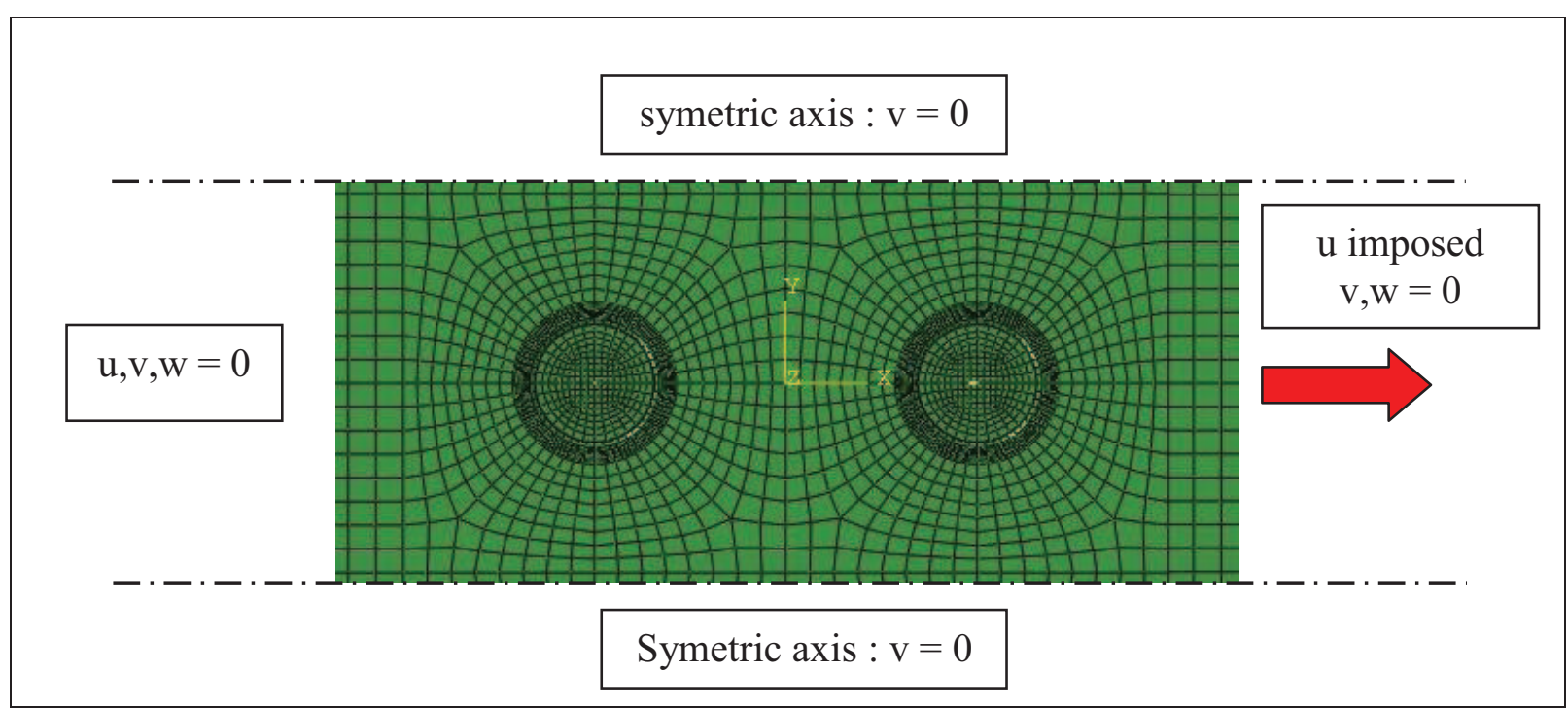


Top view of the 3D FE model

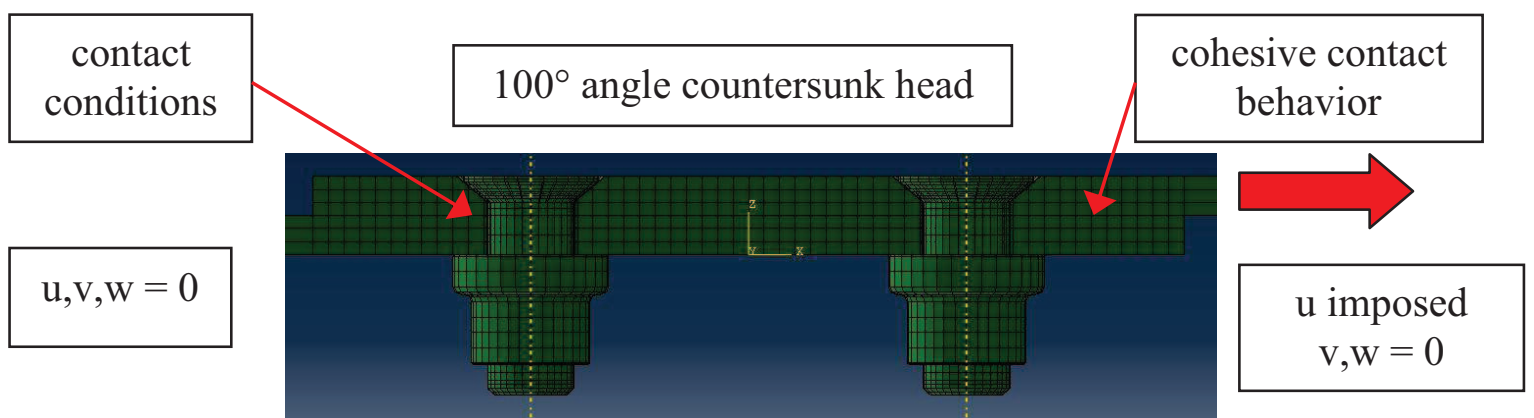

Longitudinal middle cut view of the 3D FE model

Figure 16. Mesh and boundary conditions of the 3D Finite Element model

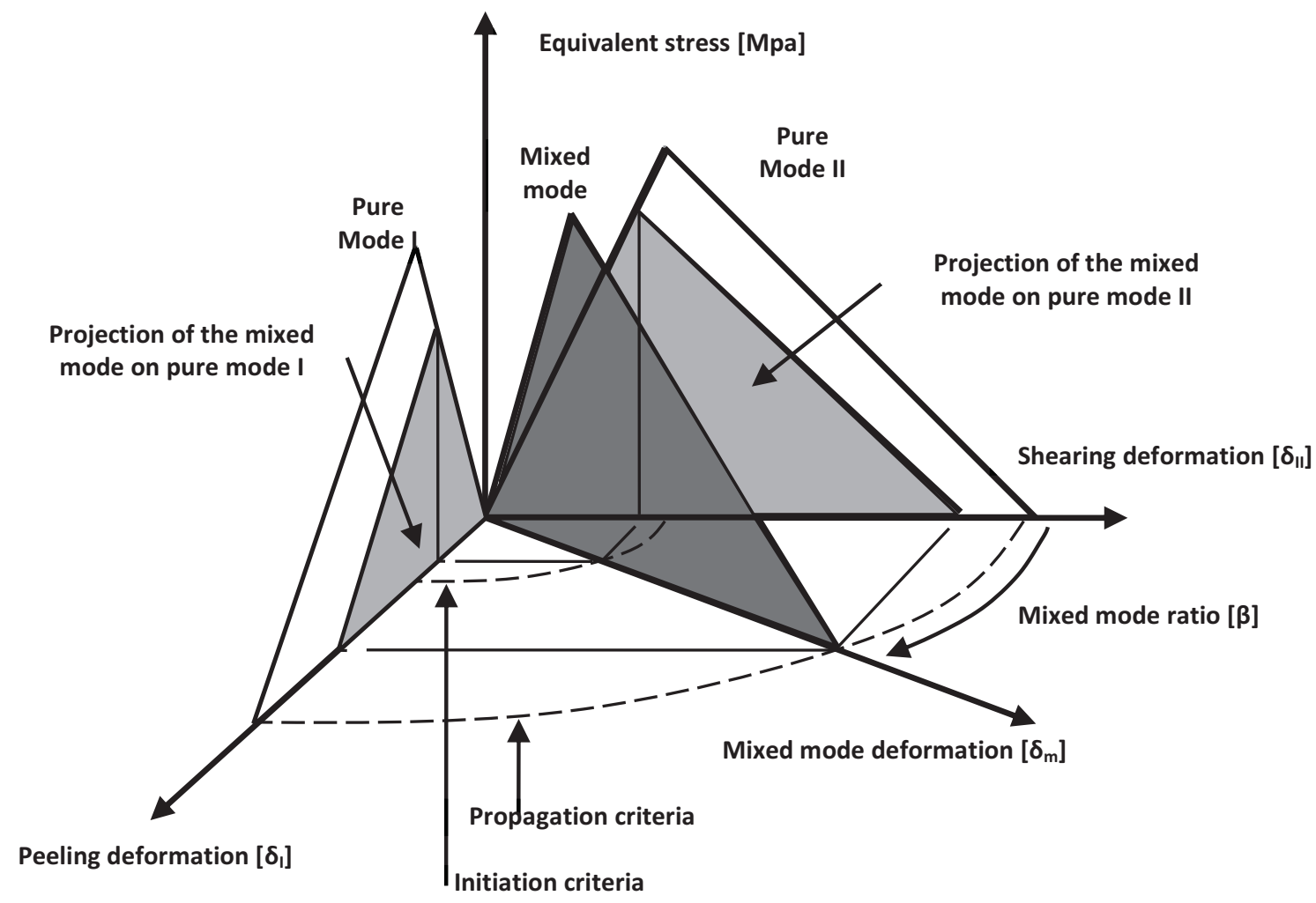

Figure 17. Mixed-mode cohesive law model (Lélias 2015) 


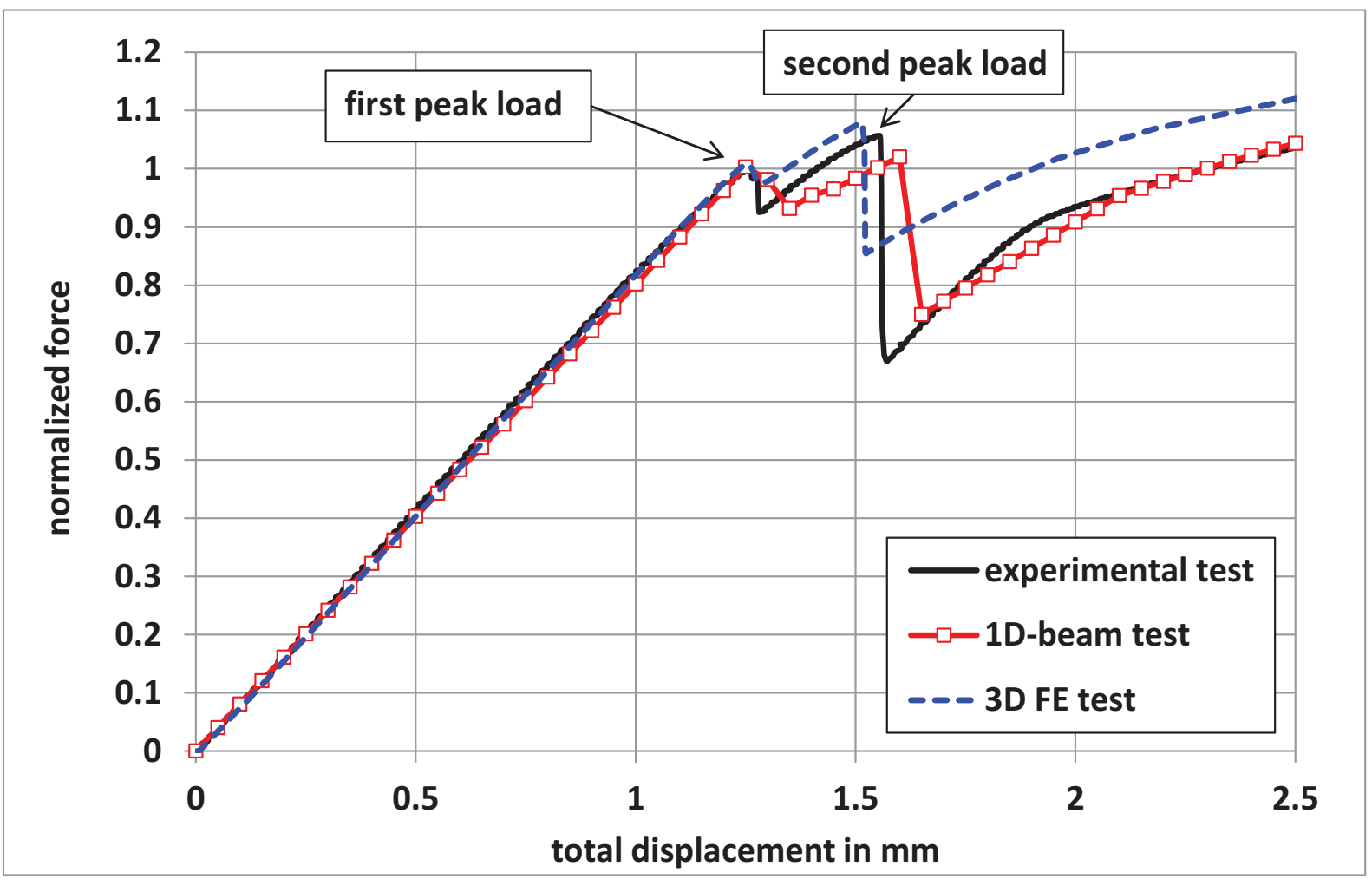

2 Figure 18. Force displacement curves for the experimental test, the 1D-beam test and the 3D FE test. The force is normalized by the first peak force experimentally measured.

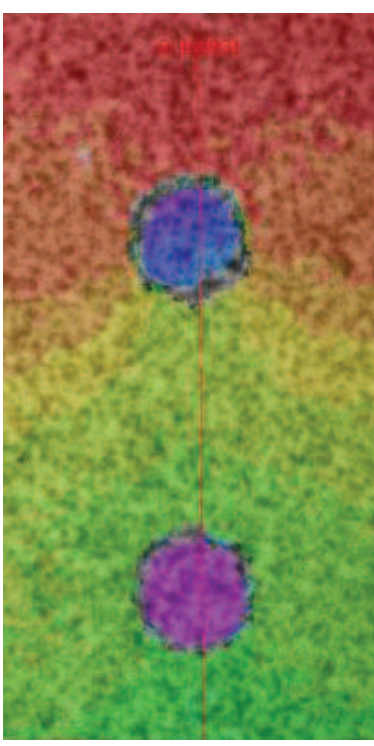

a)

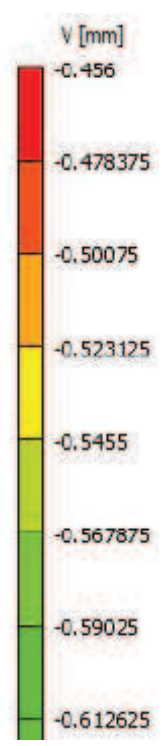

5

6 Numerical 3D FE field.

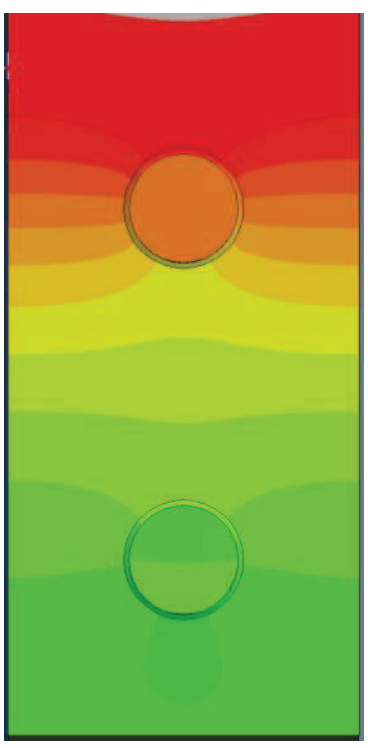

b)

Figure 19. Displacement field in the tensile direction on the overlap around the two center bolts at $0.65 \mathrm{~mm}$ total displacement of the specimen: a) Experimental field, b) 


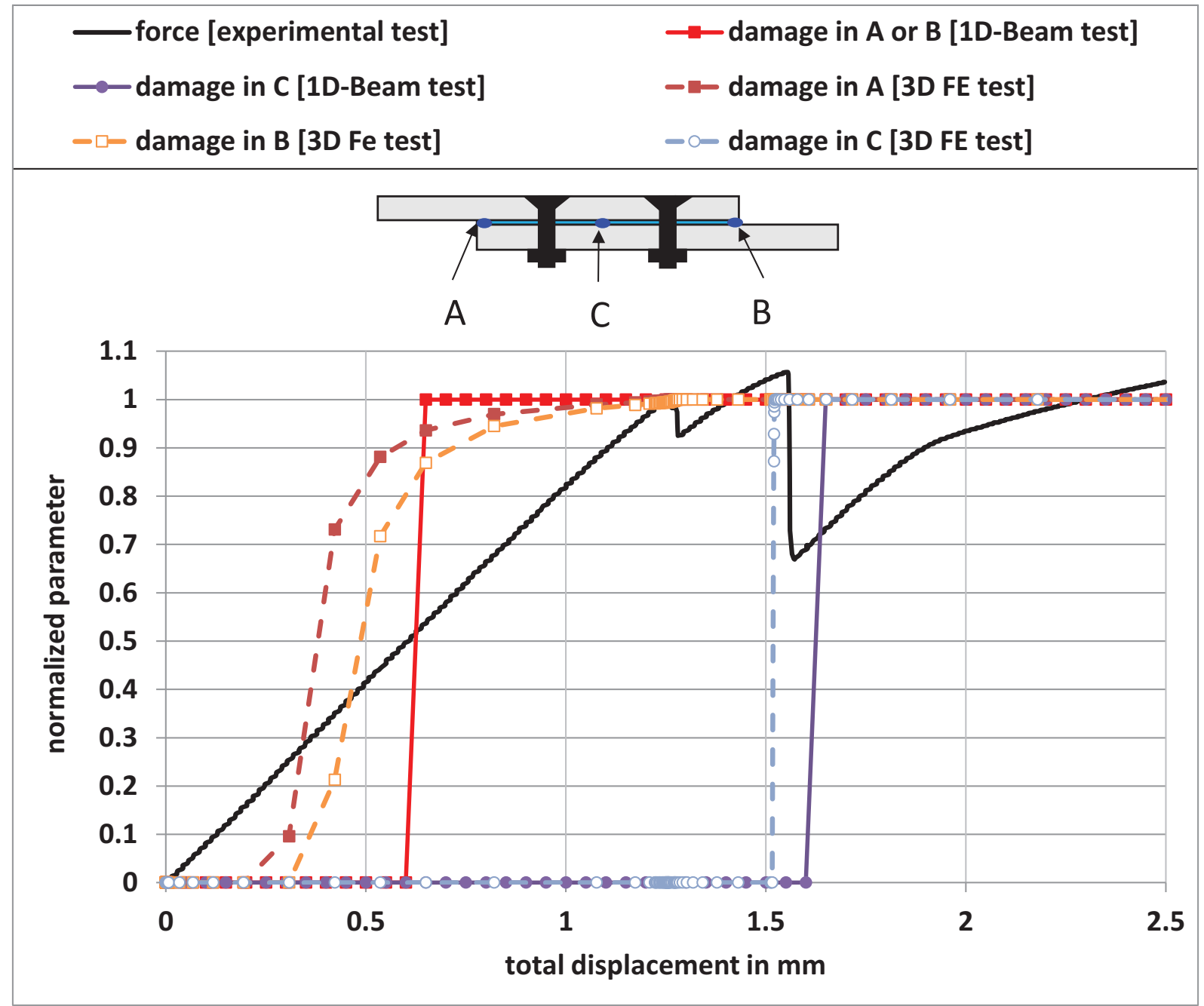

2 Figure 20. Evolution of damage parameter in point $A, B$ and $C$ according to the $1 D$-beam

3 test and the 3D FE test. $A$ is located at the extremity of the overlap near from the clamped side. $B$ is located at the other extremity. $C$ is located in the middle of the 5 overlap. 


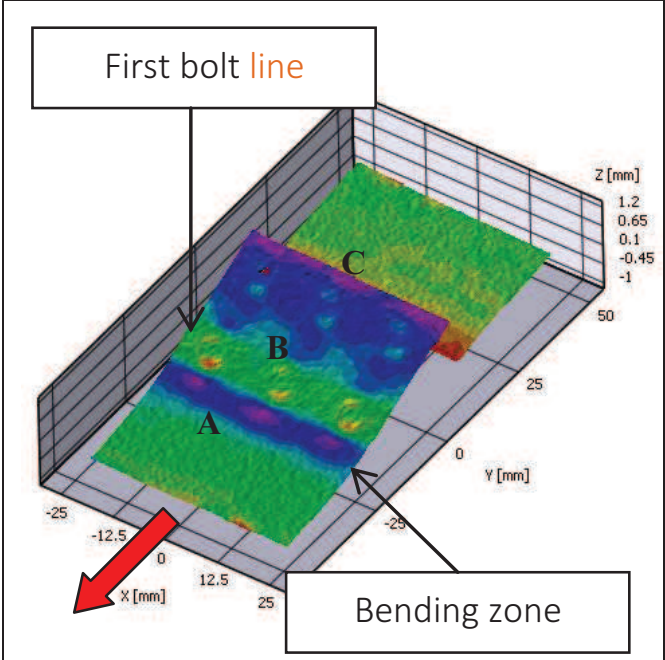

a) Before the first peak load Load $=1.0$; Disp. $=1.25 \mathrm{~mm}$
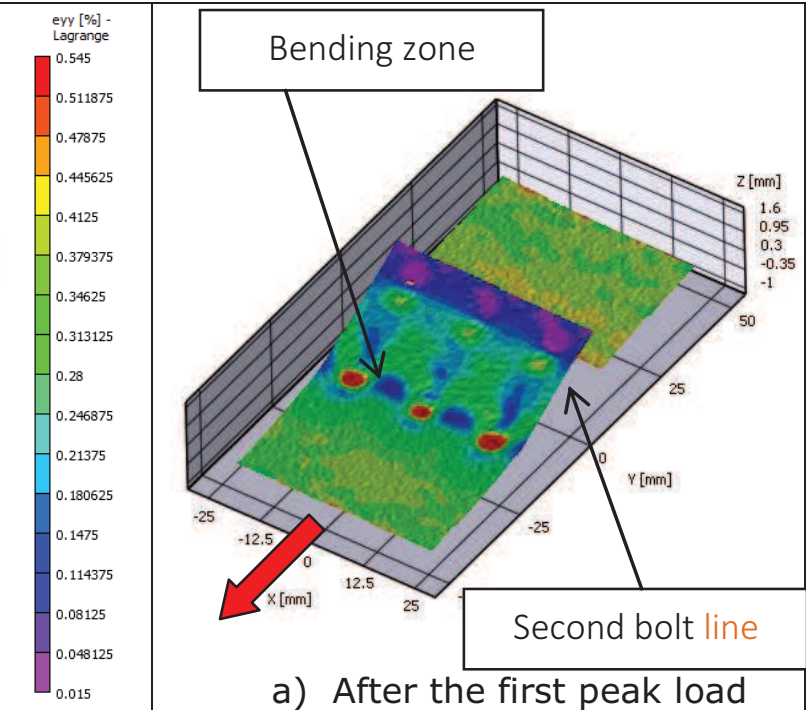

a) After the first peak load Load $=0.93$; Disp. $=1.28 \mathrm{~mm}$
Figure 21. Strain along sample in tensile direction and out-of-plane displacement, around

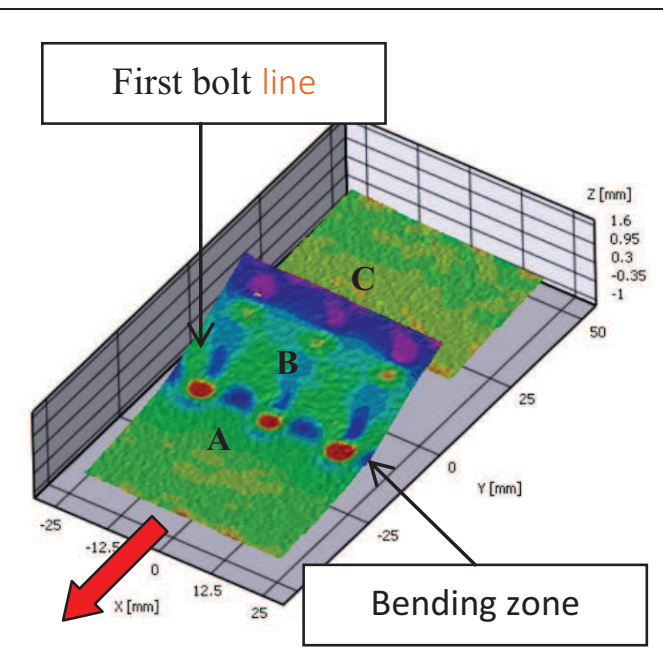

a) Before the second peak load Load $=1.05$; Disp. $=1.50 \mathrm{~mm}$

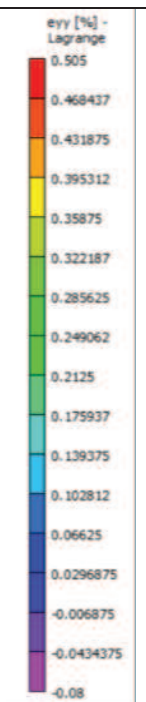

b) After the second peak load Load $=0.68$; Disp. $=1.6 \mathrm{~mm}$

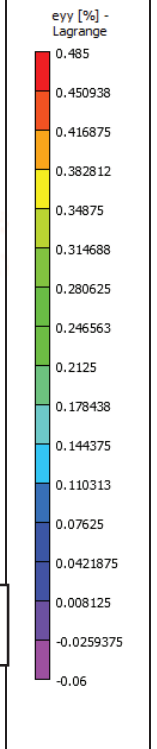
d 


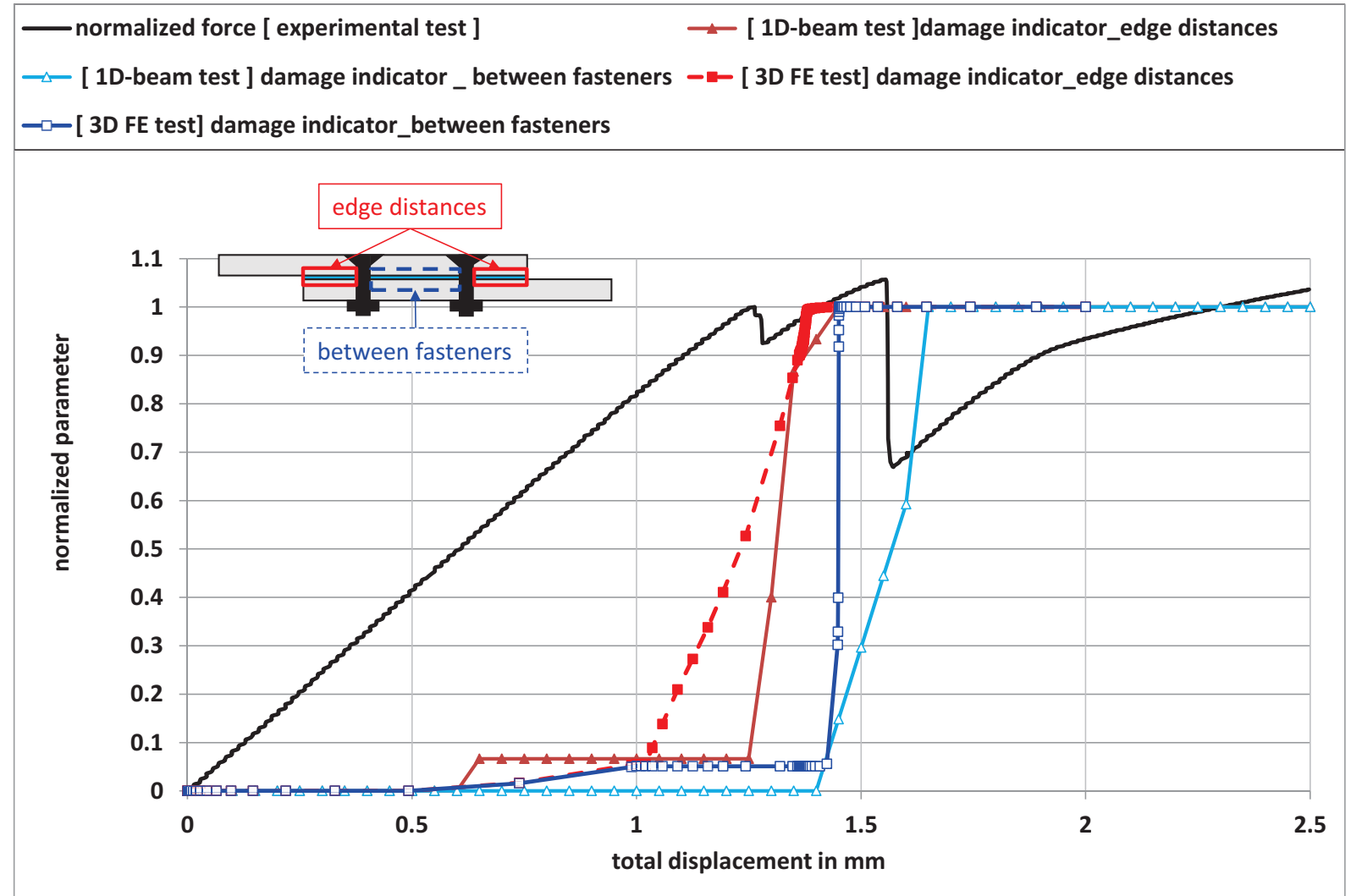

3 Figure 23. Evolution of damage indicator computed on both edge distances and between

4 the fastener lines according to the 1D-beam test and the 3D FE test.

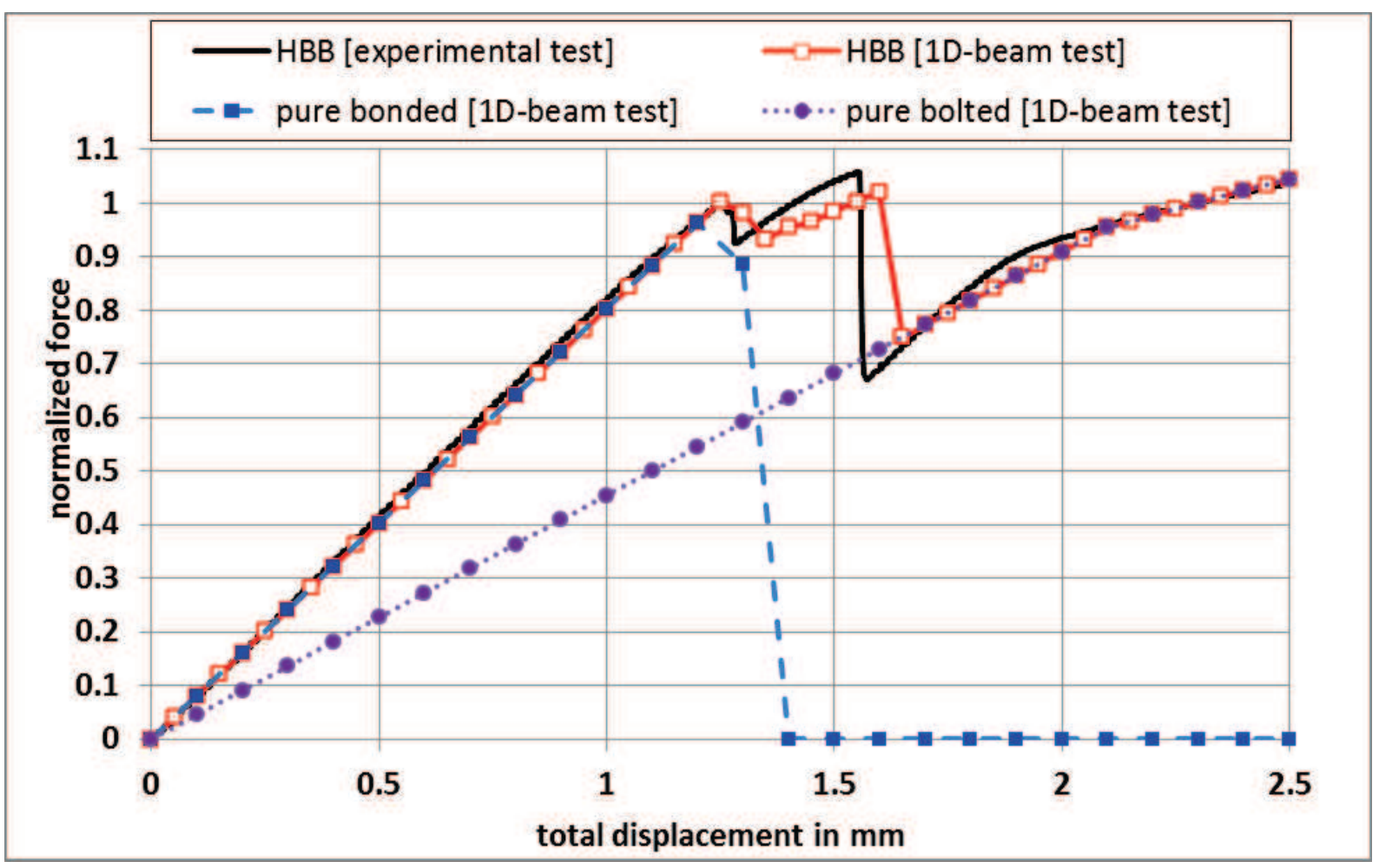


1 Figure 24. Force displacement curves for the experimental test on HBB joint and for the

2 1D-beam test on $H B B$, pure bonded and pure bolted joint. The force is normalized by the 3 first peak force experimentally measured.

4

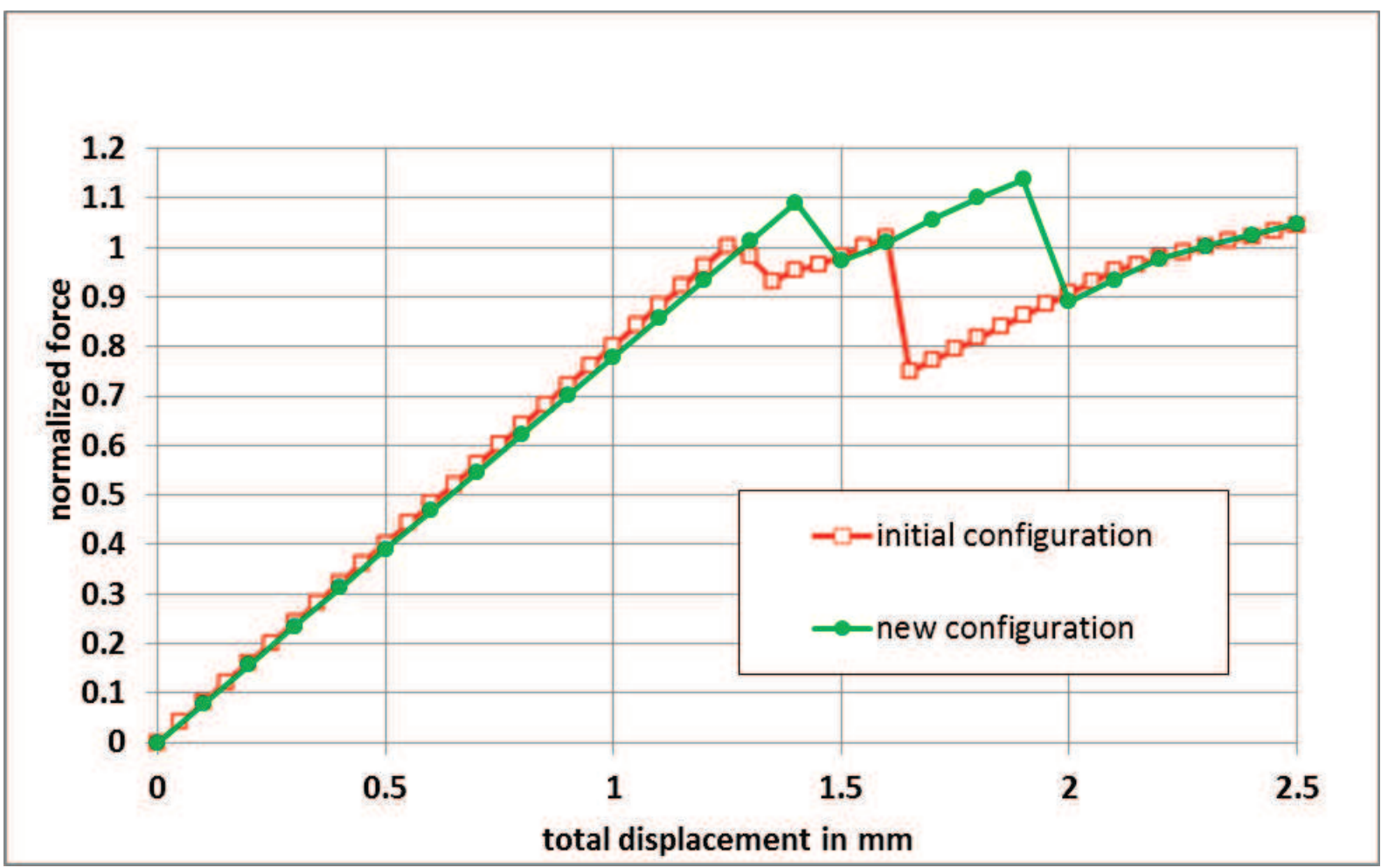

6 Figure 25. Force displacement curves for for the 1D-beam test on HBB in the initial and 7 new configurations. The force is normalized by the first peak force experimentally measured (initial configuration)

9 


\section{TABLES}

3

4 Table 1. Geometrical and mechanical parameters for the single-lap bonded joint under

5 the configuration of Goland and Reissner's theory (1944).

\begin{tabular}{|c|c|c|c|c|c|}
\hline$C_{u, w}\left(N \cdot m^{-1}\right)$ & $\mathrm{C}_{\theta}\left(\mathrm{N} \cdot \mathrm{mm} \cdot \mathrm{rad}^{-1}\right)$ & E (MPa) & $E_{1}(M P a)$ & $E_{2}(M P a)$ & G (MPa) \\
\hline $1 e^{-8}$ & $1 e^{-8}$ & 2000 & 72000 & 72000 & 800 \\
\hline e $(\mathrm{mm})$ & $e_{1}(\mathrm{~mm})$ & $e_{2}(\mathrm{~mm})$ & b $(\mathrm{mm})$ & $\mathbf{L}(\mathbf{m m})$ & $f(N)$ \\
\hline 0.1 & 1.6 & $1.6+1 e^{-8}$ & 25 & 25 & 1000 \\
\hline
\end{tabular}

6

7

8 Table 2. Geometrical parameters employed for the single-lap bonded and HBB joints.

\begin{tabular}{|c|c|c|c|c|c|c|c|}
\hline $\mathbf{e}_{\mathbf{1}}(\mathbf{m m})$ & $\boldsymbol{e}_{\mathbf{2}}(\mathbf{m m})$ & $d(\mathbf{m m})$ & $\boldsymbol{s}(\mathbf{m m})$ & $b(\mathbf{m m})$ & $I_{\mathbf{1}}(\mathbf{m m})$ & $I_{\mathbf{2}}(\mathbf{m m})$ & $e(\mathbf{m m})$ \\
\hline 2.4 & 3.2 & 10 & 20 & 20 & 40 & 40 & 0.5 \\
\hline
\end{tabular}

9

10

11 Table 3. Mechanical parameters employed for the single-lap bonded and HBB joints.

\begin{tabular}{|c|c|c|c|c|c|}
\hline $\begin{array}{c}C_{u} \\
\left(N . \mathrm{mm}^{-1}\right)\end{array}$ & $\begin{array}{c}C_{w} \\
\left(N \cdot m^{-1}\right)\end{array}$ & $\begin{array}{c}C_{\theta} \\
\left(\mathrm{N} \cdot \mathrm{mm} \cdot \mathrm{rad}^{-1}\right)\end{array}$ & $\begin{array}{c}G \\
(M P a)\end{array}$ & $\begin{array}{c}E \\
(M P a)\end{array}$ & $\begin{array}{c}f \\
(N)\end{array}$ \\
\hline 50000 & 50000 & 50000 & 100 & 280 & 1000 \\
\hline $\begin{array}{l}\left(E_{11}\right)_{1} \\
(M P a)\end{array}$ & $\begin{array}{l}\left(E_{22}\right)_{1} \\
(M P a)\end{array}$ & $\begin{array}{l}\left(G_{12}\right)_{1} \\
(M P a)\end{array}$ & $\left(v_{12}\right)_{1}$ & $\begin{array}{c}E_{2} \\
(M P a)\end{array}$ & \\
\hline 98000 & 7800 & 4700 & 0.34 & 72000 & \\
\hline
\end{tabular}

12 
1 Table 4. Material law and parameters assumed in the frame of the 3D FE model.

\begin{tabular}{|c|c|c|c|}
\hline COMPONENT & MATERIAL & LAW TYPE & LAW PARAMETERS \\
\hline adherend & aluminium & $\begin{array}{l}\text { elastic perfectly } \\
\text { plastic } \\
\text { isotropic }\end{array}$ & $\begin{array}{l}\text { Young's modulus: } 72,400 \mathrm{MPa} \\
\text { Poisson's ratio: } 0.3 \\
\text { yield stress: } 350 \mathrm{MPa}\end{array}$ \\
\hline screw & titanium & $\begin{array}{l}\text { elastic perfectly } \\
\text { plastic } \\
\text { isotropic }\end{array}$ & $\begin{array}{l}\text { Young's modulus: } 110 \mathrm{GPa} \\
\text { Poisson's ratio: } 0.3 \\
\text { yield stress: } 1100 \mathrm{MPa}\end{array}$ \\
\hline nut & steel & $\begin{array}{l}\text { elastic linear } \\
\text { isotropic }\end{array}$ & $\begin{array}{l}\text { Young's modulus: } 210 \mathrm{GPa} \\
\text { Poisson's ratio: } 0.3\end{array}$ \\
\hline $\begin{array}{c}\text { adhesive } \\
\text { layer }\end{array}$ & methacrylate & $\begin{array}{l}\text { bilinear damaging } \\
\text { evolution }\end{array}$ & $\begin{array}{l}\mathrm{k}_{\mathrm{nn}}=\mathrm{E} / \mathrm{e}=32,000 \mathrm{~N} \cdot \mathrm{mm}^{-1} \\
\mathrm{k}_{\mathrm{ns}}=\mathrm{G} / \mathrm{e}=11,000 \mathrm{~N} \cdot \mathrm{mm}^{-1} \\
\mathrm{k}_{\mathrm{nt}}=\mathrm{G} / \mathrm{e}=11,000 \mathrm{~N} \cdot \mathrm{mm}^{-1} \\
\mathrm{GIC}=0.6 \mathrm{MPa} \cdot \mathrm{mm} \\
\mathrm{GIIC}=1 \mathrm{MPa} \cdot \mathrm{mm} \\
\mathrm{GIIIC}=1 \mathrm{MPa} \cdot \mathrm{mm} \\
\sigma_{33}=10 \mathrm{MPa} \\
\sigma_{13}=25 \mathrm{MPa} \\
\sigma_{23}=25 \mathrm{MPa} \\
\mathrm{BK} \text { parameter }=1 .\end{array}$ \\
\hline
\end{tabular}

2

3 
1 Table 5. Bilinear law assumed for the fasteners.

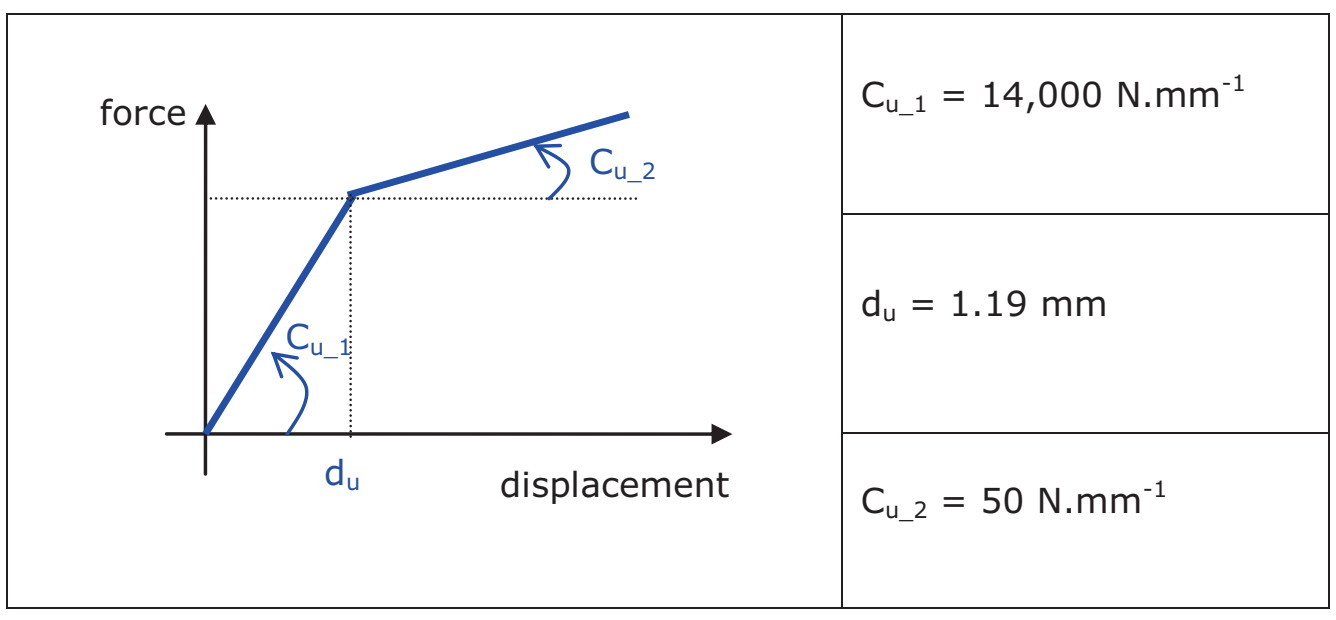

2

Table 6. Bilinear damage evolution law assumed for the adhesive layer.

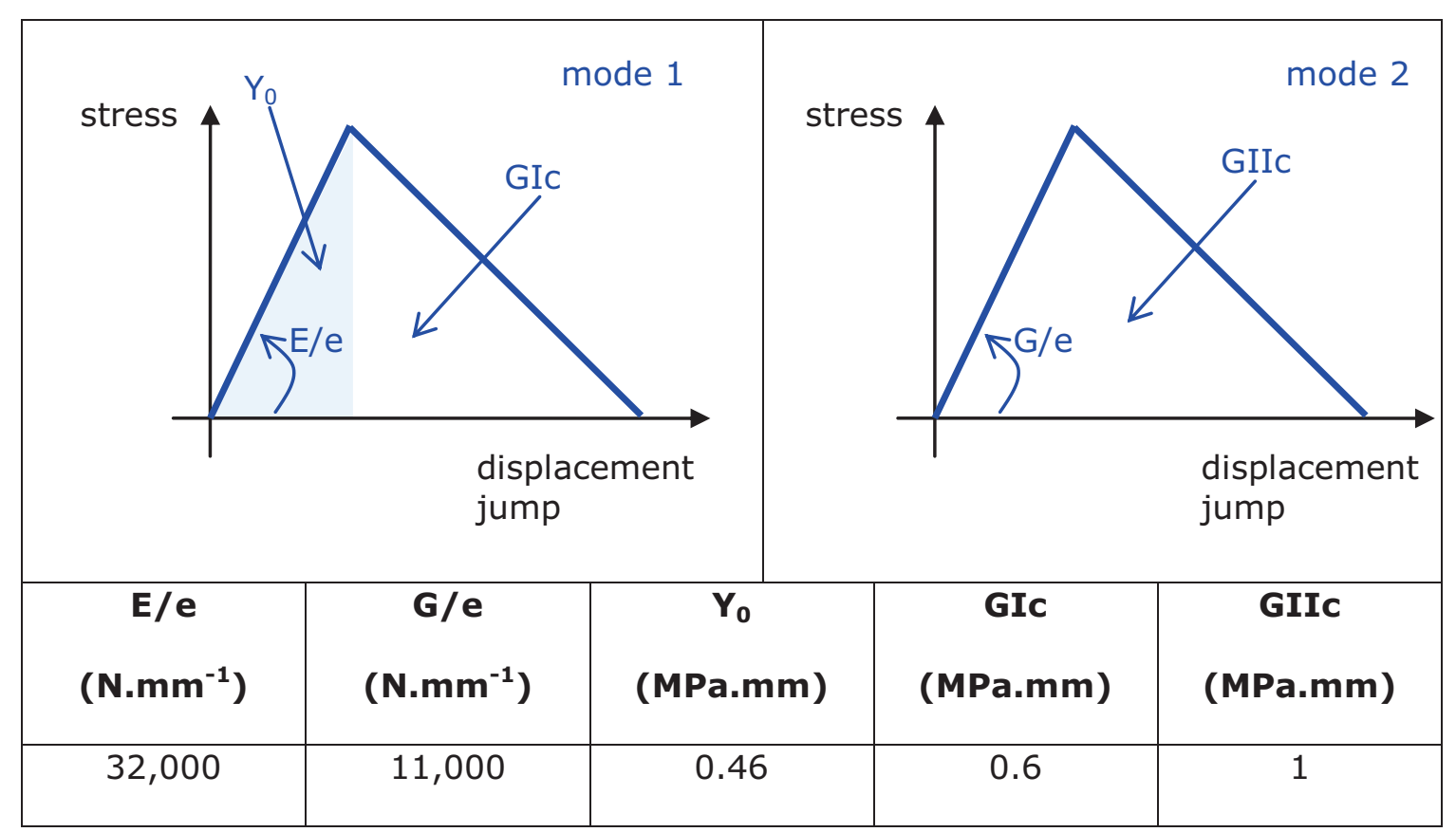

4 